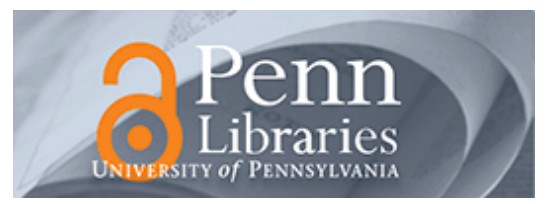

University of Pennsylvania

ScholarlyCommons

January 1984

\title{
A Diagnostic Study and Treatment Evaluation for the Cleaning of Perry's Victory and International Peace Memorial
}

Frank G. Matero

University of Pennsylvania, FGMATERO@design.UPENN.EDU

Follow this and additional works at: https://repository.upenn.edu/hp_papers

Matero, Frank G., "A Diagnostic Study and Treatment Evaluation for the Cleaning of Perry's Victory and International Peace Memorial" (1984). Departmental Papers (Historic Preservation). 6.

https://repository.upenn.edu/hp_papers/6

Reprinted from Bulletin of the Association for Preservation Technology, Volume 16, Issue 3/4, National Park Service, 1984, pages 39-51.

At the time of publication, the author was affiliated with Columbia University. Currently, February 2008 , he is a faculty member in the Historic Preservation Program at the University of Pennsylvania.

We have contacted the publisher regarding the deposit of this paper in ScholarlyCommons@Penn. No response has been received.

This paper is posted at ScholarlyCommons. https://repository.upenn.edu/hp_papers/6

For more information, please contact repository@pobox.upenn.edu. 


\title{
A Diagnostic Study and Treatment Evaluation for the Cleaning of Perry's Victory and International Peace Memorial
}

\begin{abstract}
To commemorate the naval victory of Commodore Oliver Hazard Perry during the War of 1812, a monument known as Perry's Victory and International Peace Memorial was planned and erected on South Bass Island in Lake Erie. Begun in 1912 in the centennial year of Perry's victorious battle, the winning design was a massive Doric column of granite and concrete set in a stepped plaza. Completed in 1915, the memorial remains the largest Doric column actually built. In August of 1981, a conservation study of the memorial column was conducted by the North Atlantic Historic Preservation Center, National Park Service, to evaluate potential techniques for the cleaning of the exterior granite surfaces and to provide information for long-term monitoring of the ambient and internal wall conditions of the column. In order to achieve these goals, an evaluation program was developed based on archival research, field testing, and laboratory analysis for the selection of the most appropriate cleaning and monitoring methods.
\end{abstract}

\section{Comments}

Reprinted from Bulletin of the Association for Preservation Technology, Volume 16, Issue 3/4, National Park Service, 1984, pages 39-51.

At the time of publication, the author was affiliated with Columbia University. Currently, February 2008, he is a faculty member in the Historic Preservation Program at the University of Pennsylvania.

We have contacted the publisher regarding the deposit of this paper in ScholarlyCommons@Penn. No response has been received. 


\title{
A Diagnostic Study and Treatment Evaluation for the Cleaning of Perry's Victory and International Peace Memorial
}

\author{
Frank G. Matero \\ Bulletin of the Association for Preservation Technology, Vol. 16, No. 3/4, National Park Service. \\ (1984), pp. 39-51.
}

Stable URL:

http://links.jstor.org/sici?sici=0044-9466\%281984\%2916\%3A3\%2F4\%3C39\%3AADSATE\%3E2.0.CO\%3B2-O

Bulletin of the Association for Preservation Technology is currently published by Association for Preservation Technology International (APT).

Your use of the JSTOR archive indicates your acceptance of JSTOR's Terms and Conditions of Use, available at http://www.jstor.org/about/terms.html. JSTOR's Terms and Conditions of Use provides, in part, that unless you have obtained prior permission, you may not download an entire issue of a journal or multiple copies of articles, and you may use content in the JSTOR archive only for your personal, non-commercial use.

Please contact the publisher regarding any further use of this work. Publisher contact information may be obtained at http://www.jstor.org/journals/APTech.html.

Each copy of any part of a JSTOR transmission must contain the same copyright notice that appears on the screen or printed page of such transmission.

JSTOR is an independent not-for-profit organization dedicated to and preserving a digital archive of scholarly journals. For more information regarding JSTOR, please contact support@jstor.org. 


\title{
A DIAGNOSTIC STUDY AND TREATMENT EVALUATION FOR THE CLEANING OF PERRY'S VICTORY AND INTERNATIONAL PEACE MEMORIAL
}

\author{
Frank G. Matero*
}

To commemorate the naval victory of Commodore Oliver Hazard Perry during the War of 1812, a monument known as Perry's Victory and International Peace Memorial was planned and erected on South Bass Island in Lake Erie. Begun in 1912 in the centennial year of Perry's victorious battle, the winning design was a massive Doric column of granite and concrete set in a stepped plaza. Completed in 1915, the memorial remains the largest Doric column actually built. In August of 1981, a conservation study of the memorial column was conducted by the North Atlantic Historic Preservation Center, National Park Service, to evaluate potential techniques for the cleaning of the exterior granite surfaces and to provide information for longterm monitoring of the ambient and internal wall conditions of the column. In order to achieve these goals, an evaluation program was developed based on archival research, field testing, and laboratory analysis for the selection of the most appropriate cleaning and monitoring methods.

\section{Description and Construction History}

In order to assess both the previous and existing conditions of the column masonry, documentation describing the original building materials and construction techniques was first consulted. Primary sources included the architects' original plans, elevations, sections and details; however, these documents proved to be somewhat inaccurate due to changes apparently made during construction. Of far greater value was the enormous collection of construction photographs (over 400) taken by Otto G. Herbster for the contractor, J.C. Robinson and Son from 1912 to 1915 . Studied collectively, these photographs document the entire construction of the column at every stage from foundation excavation and stone delivery to finish cleaning. Viewed individually, the photographs provide invaluable information regard- ing the specific materials and techniques that were actually employed for each phase of work.

The masonry construction of the column can best be described as an integral granite and concrete hollow shaft where the shaft interior (above the lower elevator landing) is of constant diameter $\left(27^{\prime}-6^{\prime \prime}\right)$ and the exterior walls taper from $9^{\prime}-0^{\prime \prime}$ at the base to $4^{\prime}-0^{\prime \prime}$ at the top. The exterior stonework is range ashlar or cut stone masonry where the stones are carefully squared, finely dressed, and arranged in tight, continuous, and uniform courses. The surface of the stonework exhibits an unpolished finish marked by faint parallel ridges most probably produced by patent-hammering. Tooling is irregular and unpronounced. All stonework was originally bedded and pointed with a Portland cement mortar and subsequently repointed and caulked in at least two repair campaigns. Each course of granite consists of thirty (30) blocks about four and one-half feet high and approximately seven feet across the flute or exterior concave face. Alternating courses of blocks vary in thickness (depth) from 2'-0" to $3^{\prime}-0^{\prime \prime}$. Seventy-eight (78) vertical courses form the exterior of the shaft proper measuring approximately 282 feet high in total.

Of greater intricacy is the construction of the column capital. Here heavy beams are bracketed from the tower where they support substantial falsework which in turn supports the granite blocks composing the echinus. The inside face of the stone is cut to form dovetails, or keys, which, with steel reinforcing, lock the concrete to the stone. Cantilevered from and above this construction is the abacus, 47 feet square and $7^{\prime}-8^{\prime \prime}$ deep, which actually forms the observation gallery. The echinus and abacus together are approximately 18 feet deep.

According to Herbster's photographs and detailed contemporary accounts of the construction techniques employed, it appears that the column was built in successive levels by setting each course of granite first,

*Frank G. Matero is an Architectural Conservator, Assistant Professor of Architecture, Columbia University. 


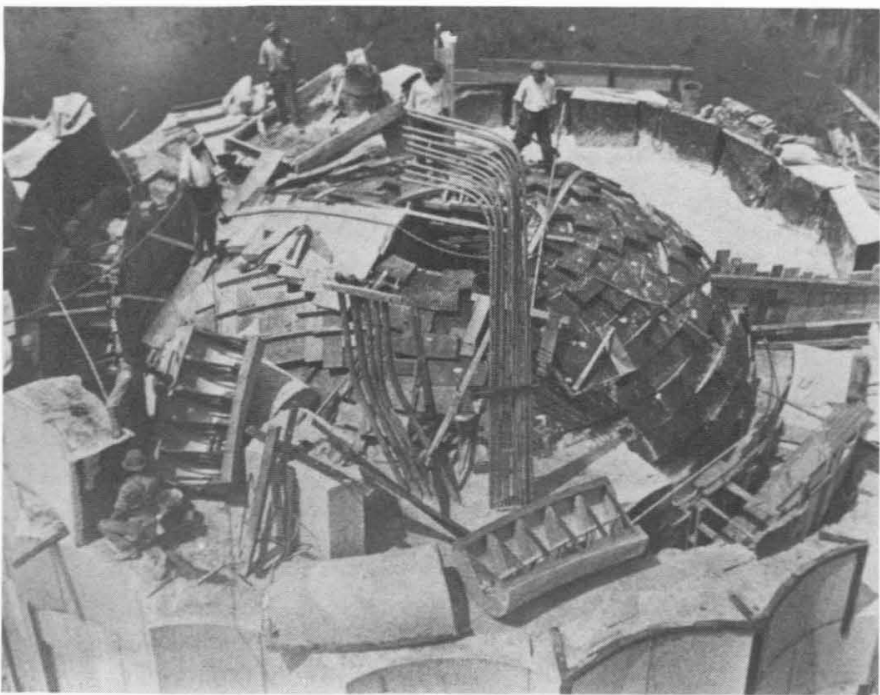

1. Perry Memorial: Construction photograph (1913).

inserting wooden forms within the shaft and filling the space between with concrete which was fed from the ground and pulled up through the shaft interior (Fig. 1). In order to insure integration between the two masonry systems, the stonework was bonded into the concrete backing by laying alternate courses of granite $\left(2^{\prime}-0^{\prime \prime}\right.$ and $3^{\prime}-0^{\prime \prime}$ in depth) thus producing a keying of the two materials. In addition, each individual block of stone was anchored into the concrete matrix with galvanized iron clamps ( 2 per stone). Prior to the pouring of the concrete, the back and side faces of all stonework were coated on site with a damp-proofing paint (Fig. 1), identified by Roy Robinson as 'RIW Paint', a then popular bituminous damp-proof coating manufactured by Toch Brothers of New York City.

By September of 1914, approximately 97 percent of the masonry work had been completed. Construction photographs indicate that at this time or shortly thereafter, the granite ashlar facing was cleaned free of all surface dirt and mortar laitence by abrasive blasting (presumably with sand) and the final pointing executed. The column was completed and opened to the public on June 13, 1915.

Based on existing construction documents and petrographic analysis of the stone itself, it is certain that the granite employed as facing on the entire column, upper plaza benches and parapet facing, plaza stairs, and lower plaza border stones is Milford Pink Granite, a light pinkish biotite granite which was quarried near Milford, Massachusetts about 16 miles southeast of Worcester. The stone is of medium to coarse texture, with a slight tendency toward banding or parallelism which is attributed to flow structure. When the rock is cut parallel with the flow structure, the characteristic black spots of mica are largest because the mica flakes parallel this direction. Also characteristic of this granite is the blue color of its individual quartz grains. Milford Pink Granite achieved popular commercial status, particularly for carved and architectural work, in the early 20 th century. It was used extensively in many large build- ings in the Eastern and Middle-Western states and most notably for the construction of the now demolished Pennsylvania Railroad Station in New York City.

\section{Deterioration History}

A chronological study of the disfigurement of the column's granite surfaces was conducted by reviewing all previous photographs of the exterior in conjunction with the recently prepared survey documents and conditions photographs. Wherever possible, both historic and modern views were matched for comparison. A comparative analysis of the various forms of surface disfigurement and general masonry conditions (where observation was possible) is summarized in the observations and conclusions below.

The earliest description of the conditions of the column masonry is Robinson's account of his return to the site in 1916, just one year after the monument's completion. Robinson indicated that at this time the surface of the granite was streaked black below the build joints for a considerable depth. This was attributed by Robinson to the mechanical breakdown of the RIW paint and its eventual mixing with rainwater to form a staining compound. Although this phenomenon and Robinson's explanation of it are difficult to assess without supporting documentation, it seems unlikely that this process would have begun so soon after construction. Moreover, discussions with several masonry con-

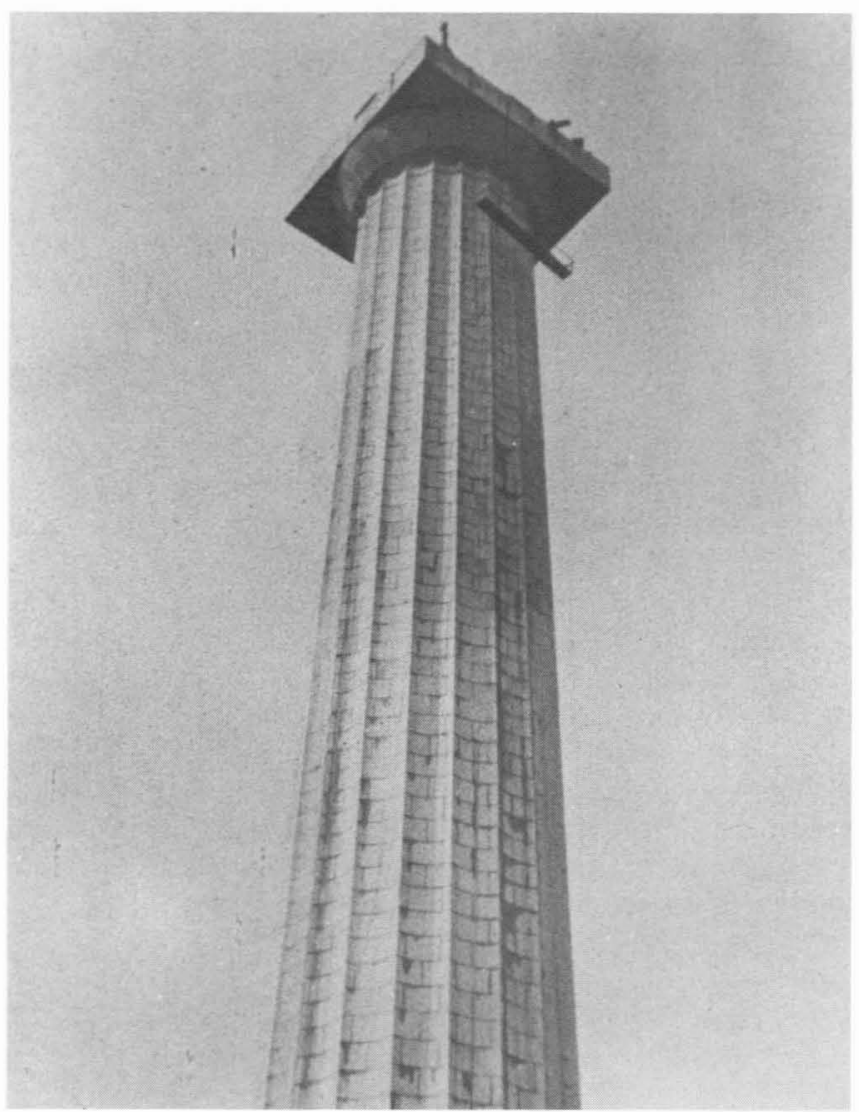

2. Perry Memorial: Construction photograph (1914). 


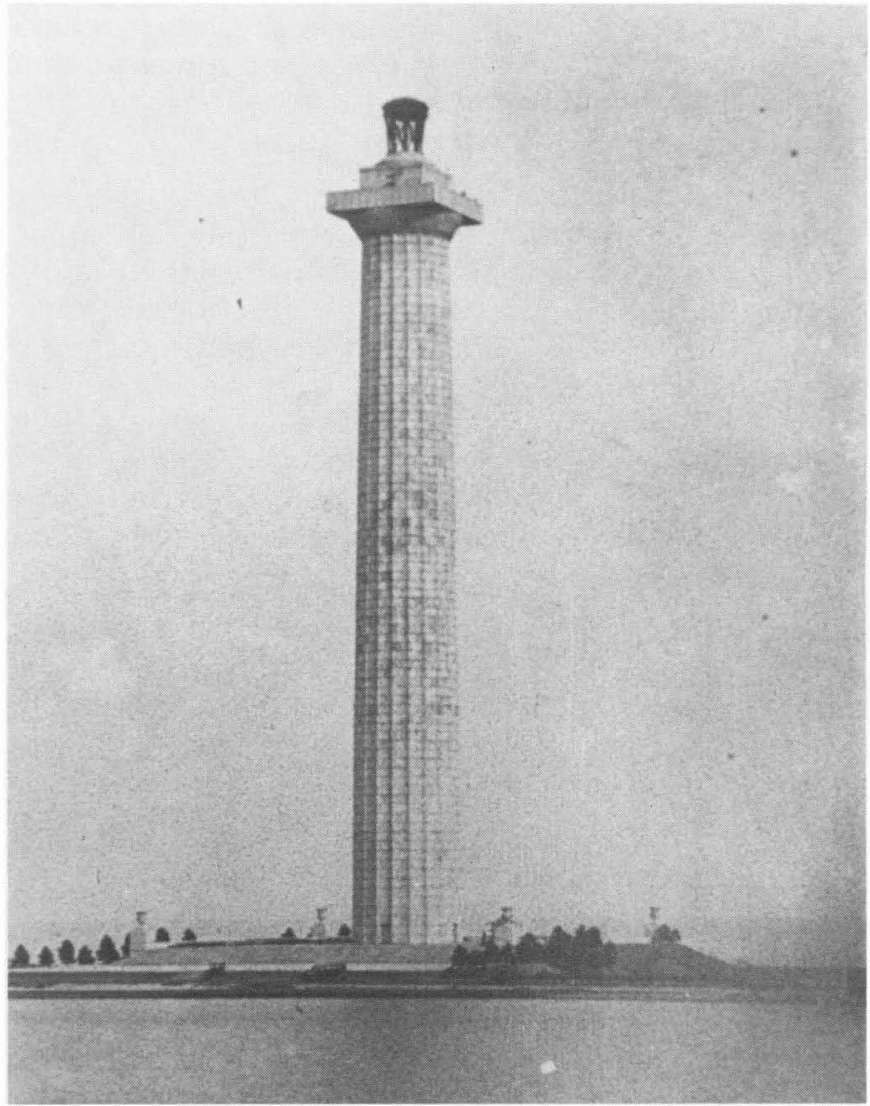

3. Perry Memorial Column and Plaza (c. 1920).
15). These conditions can be observed in a detail of the column base taken in 1983 (Fig. 6).

Despite repeated attempts in 1952 (Figs. 7-9) and 1964 (Figs. 10-12) to remove the surface staining using low pressure abrasive cleaning, the dark discoloration was not effectively removed and white deposits were removed only temporarily. Both conditions still prevailed in 1981 (Figs. 13 \& 14).

\section{Maintenance History}

A detailed maintenance history of the monument is difficult to reconstruct because few records are available which carefully document either cyclical or remedial repairs. An examination of several exterior photographs taken of the column during restoration/maintenance work, physical investigation of specific areas, and a review of both published and unpublished accounts, has made it possible to compile the following brief chronology of masonry related treatments:

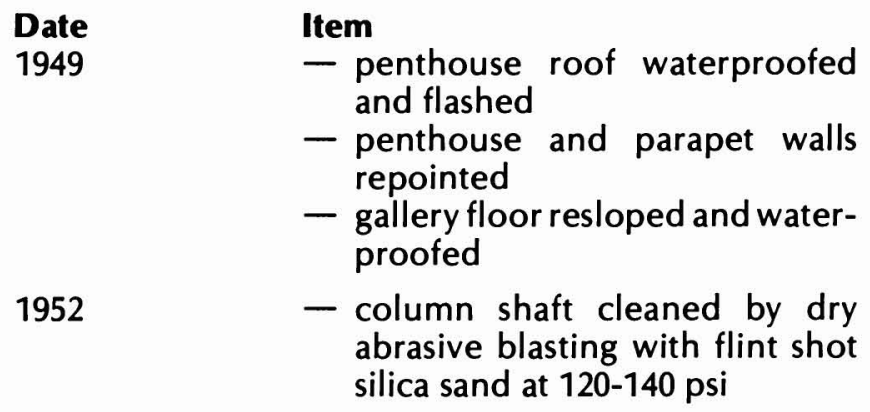

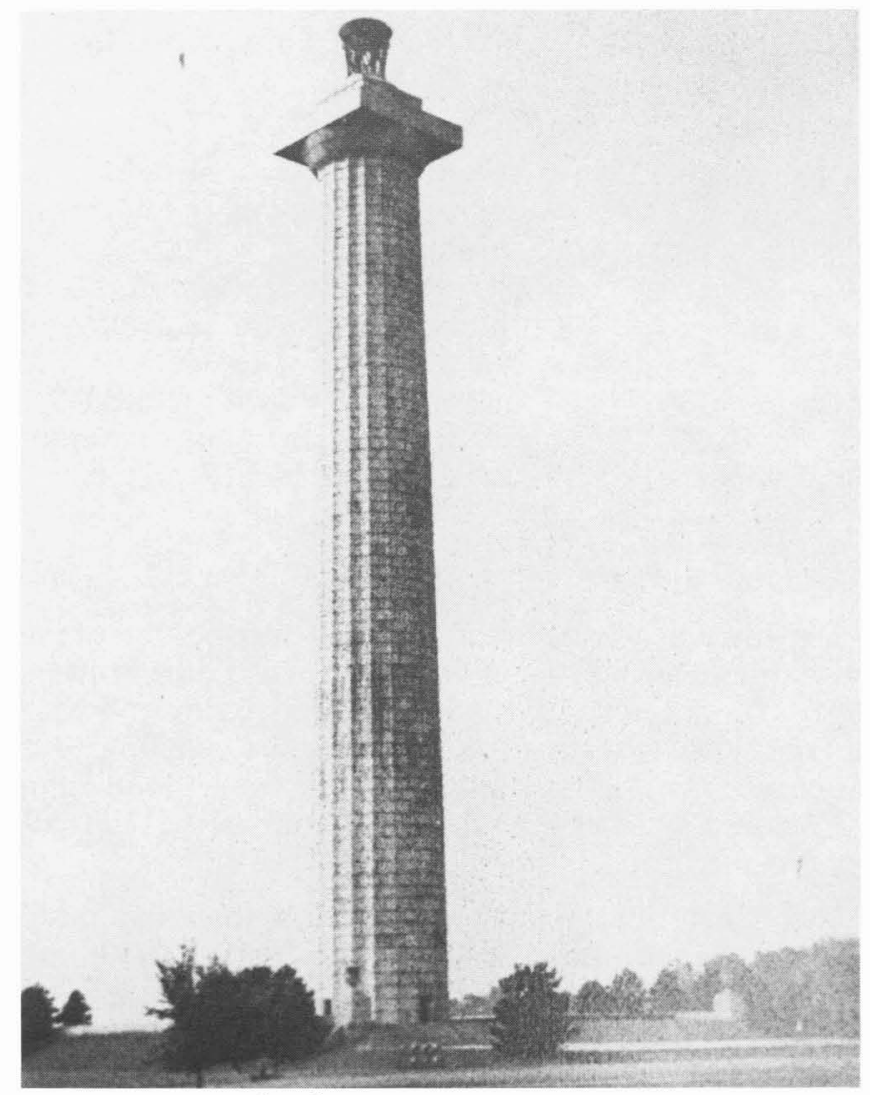

4. Perry Memorial Column (c. 1928). tractors of long-standing experience revealed that the use of RIW paint was a well-established practice in the construction industry at that time and the phenomenon described by Robinson was never observed.

Nonetheless, staining of some sort can be seen in several construction photographs taken prior to sandblasting and repointing (Fig. 2), as well as in early photographs of the completed monument in ca. 1920 (Fig. 3). While it would be reasonable to assume the entrapment of water within the open joints of the column prior to final pointing and hence the formation of continually wet areas (possibly the dark staining in the 1914 photograph), a similar staining phenomenon observed in the later photographs (after cleaning and pointing) cannot be attributed to these same conditions (i.e., water in open joints). Viewed collectively, the photographs spanning the years between 1920 and the present indicate that surface staining has been and continues to be an active process and one of serious concern due to its apparent acceleration in recent years (Figs. 3-13).

Close examination of the historic photographs indicates that the staining has always been two distinct systems: 1) a dark discoloration following the perimeter of both edges of the bed and head joints and frequently on the stone faces beginning at the base of the adjacent upper head joints (Fig. 16), and (2) a white streaky deposit always found below the head and bed joints and sometimes continuing onto the stone face below (Fig. 


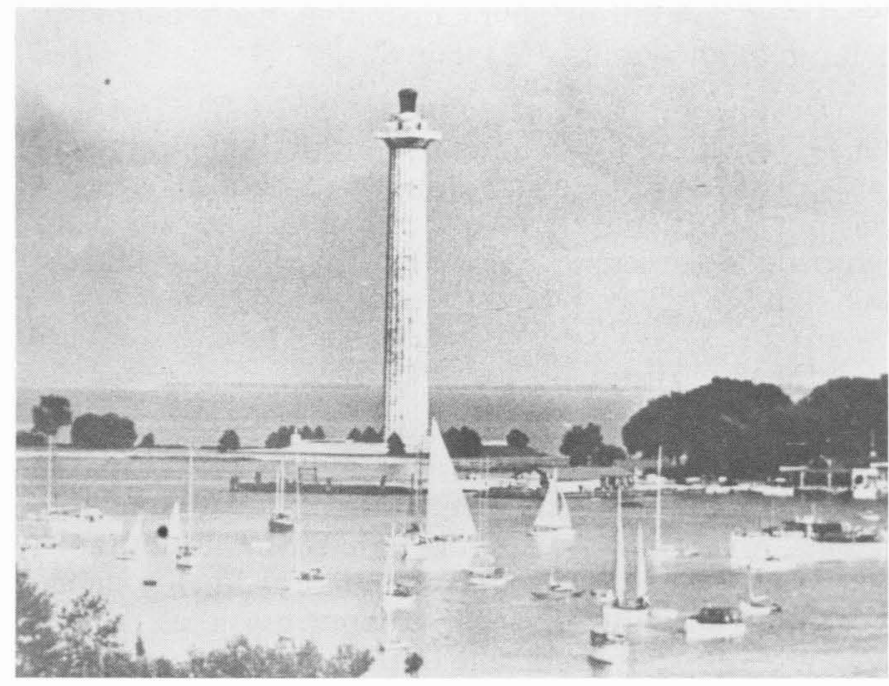

5. Perry Memorial Column (c. 1930).

- carbonate deposits removed by hand with 'metal tools'

- joints raked and repointed with a mix of 1 part cement, 1/2 part hydrated lime putty and 3 parts sand

- select composite patching executed with a mix of 1 part 'special patching cement' and 3 parts pulverized granite

- all undeveloped surface cracks waterproofed with DRIWAL ${ }^{\circledR}$ manufactured by Glidden Co. of Cleveland

1963-1964

(Figs. 10, 11 \& 12) - column shaft cleaned with wet aggregate blasting at low pressure

- all joints raked, repointed and caulked with an elastomeric sealant

- masonry coated with Thoro $777{ }^{\circledR}$ silicone waterproofing manufactured by Thoroseal Products

\section{Conditions Survey}

A visual examination of the exterior condition of the column masonry surfaces was conducted during June, 1981. The purpose of this survey was to examine all surface staining, as well as the previous cleaning tests executed. Inspection was completed from the ground with the aid of field binoculars, and from partial scaffolding erected around the column.

The exterior face of the column shaft exhibited damp white crumbly deposits of an accretive nature up to $2.5 \mathrm{~cm}$ thick (maximum) (Fig. 15). These deposits were only found below the head and bed joints and sometimes across the entire face of a stone. Associated with these white deposits and occurring along their outer perimeter was a hard, thin glassy deposit, clear to milkywhite in color (Figs. 15-17). The heaviest concentration of these staining deposits existed around the lower fifth of the shaft, particularly between courses 10-15 (Fig. 14).

A second form of staining or discoloration was also found along the border edges of the stone joints (Fig. 16). This condition can best be described as dark narrow banding following both edges of the bed and head joints and in some cases extending over the entire face of a stone. Unlike the accretive staining, this discoloration exists within the first few millimeters below the granite surface. While these two forms of staining often occurred together (Fig. 15), the latter condition was far more prevalent over the entire exterior surfaces of the monument's stonework.

In addition to surface staining, related exterior structural damage was observed involving major vertical cracking extending over several courses in length (south side most seriously), surface spalling, and defective joints.

\section{Exterior Masonry Staining}

Examination of both historical and recent survey documents indicates that there has been overall surface staining of the column's exterior masonry since 1920. Based on an understanding of the column's construction detailing and its staining history, it can be concluded that this phenomenon is directly due to the migration of water through the concrete core and out through open joints and fissures onto the surface of the stonework (Fig. 17). Investigations performed during the disassembly of the observation gallery parapet revealed a general disassociation of the concrete core with the stone facing. This separation (also observed in other integrally poured concrete and unit masonry systems) has resulted in fissures up to 1 inch thick which, in combination with open and defective joints, have allowed condensed water vapor and rainwater to flow down into the column shaft. This water passing through the concrete core and bed-

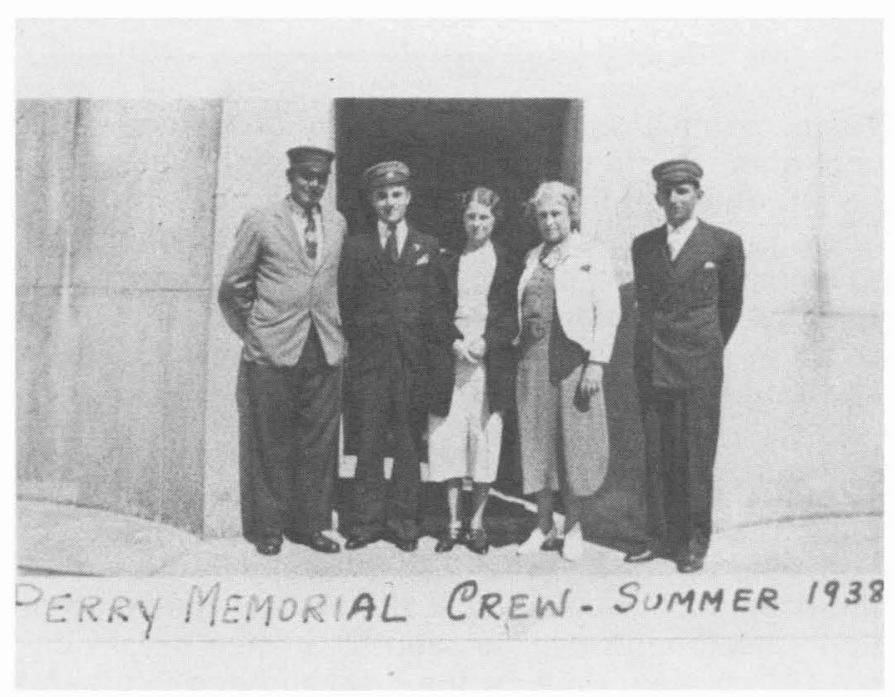

6. Base of Perry Memorial Column (1938). 
ding mortar repeatedly dissolves soluble material, which is redeposited through carbonation and evaporation around open joints and fissures and onto the ashlar surfaces. These white accretive deposits have been identified as calcium carbonates; however, they also include complex silicate compounds (Di and Tri-calcium silicate) which can be observed as the clear to milky-white glaze around the edges of the thicker carbonate deposits, as well as around the face edges of the joints. It is, in fact,

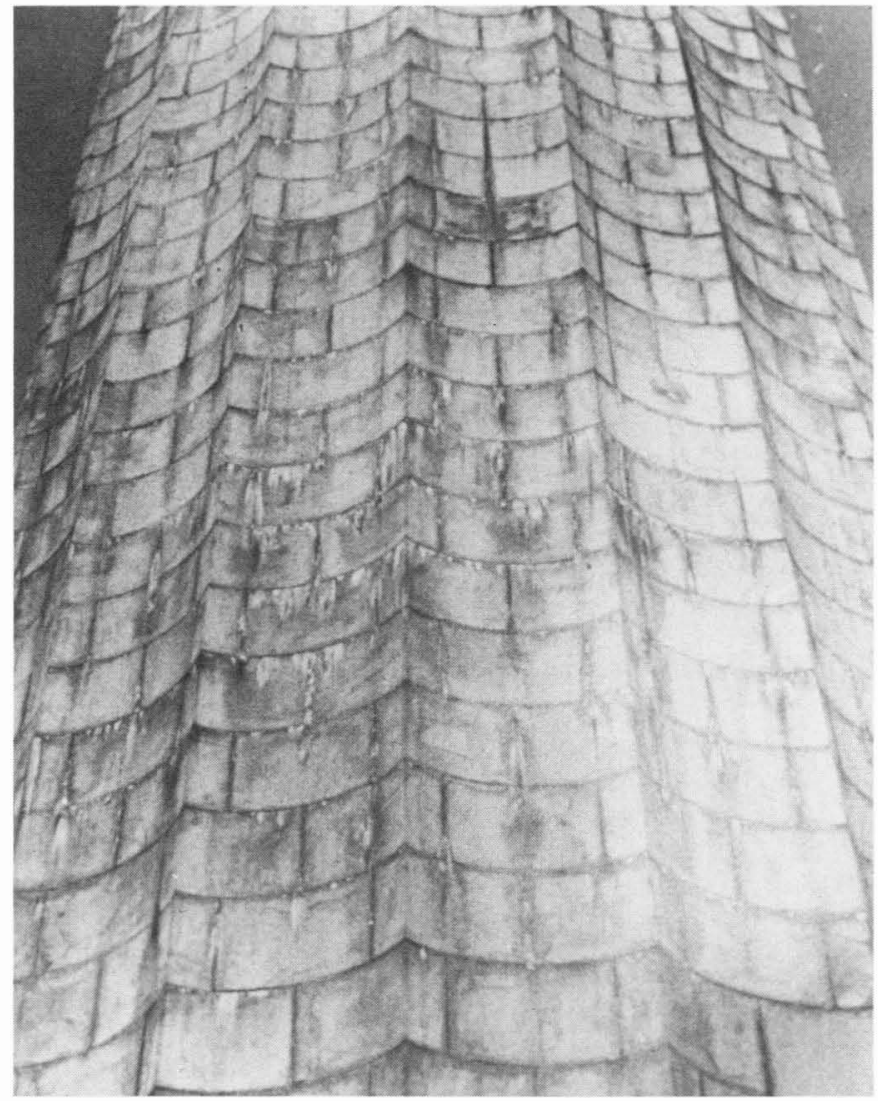

7. Perry Memorial Column (c. 1952).
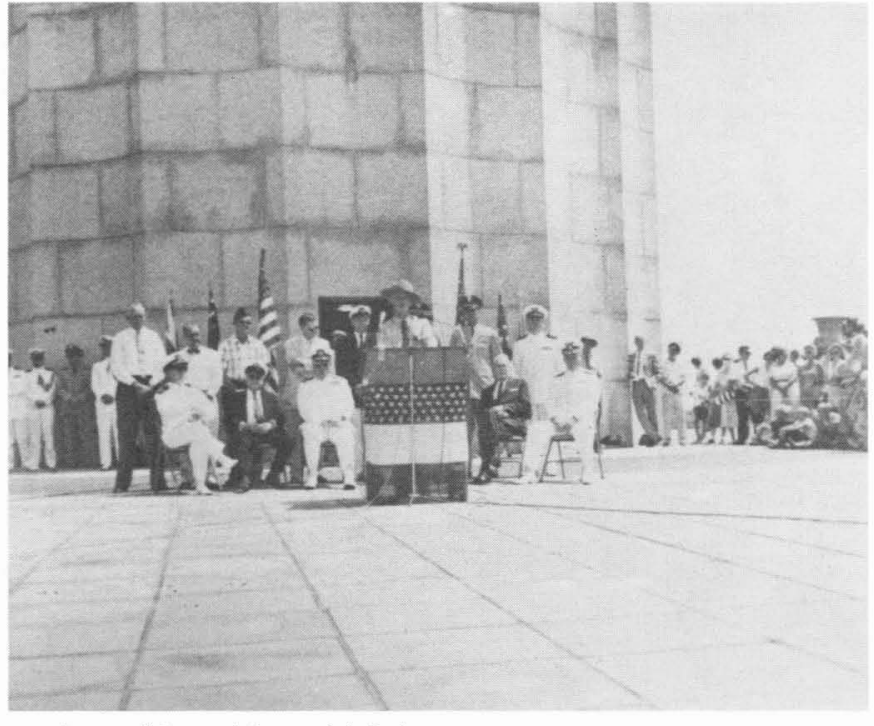

9. Base of Perry Memorial Column (1959).

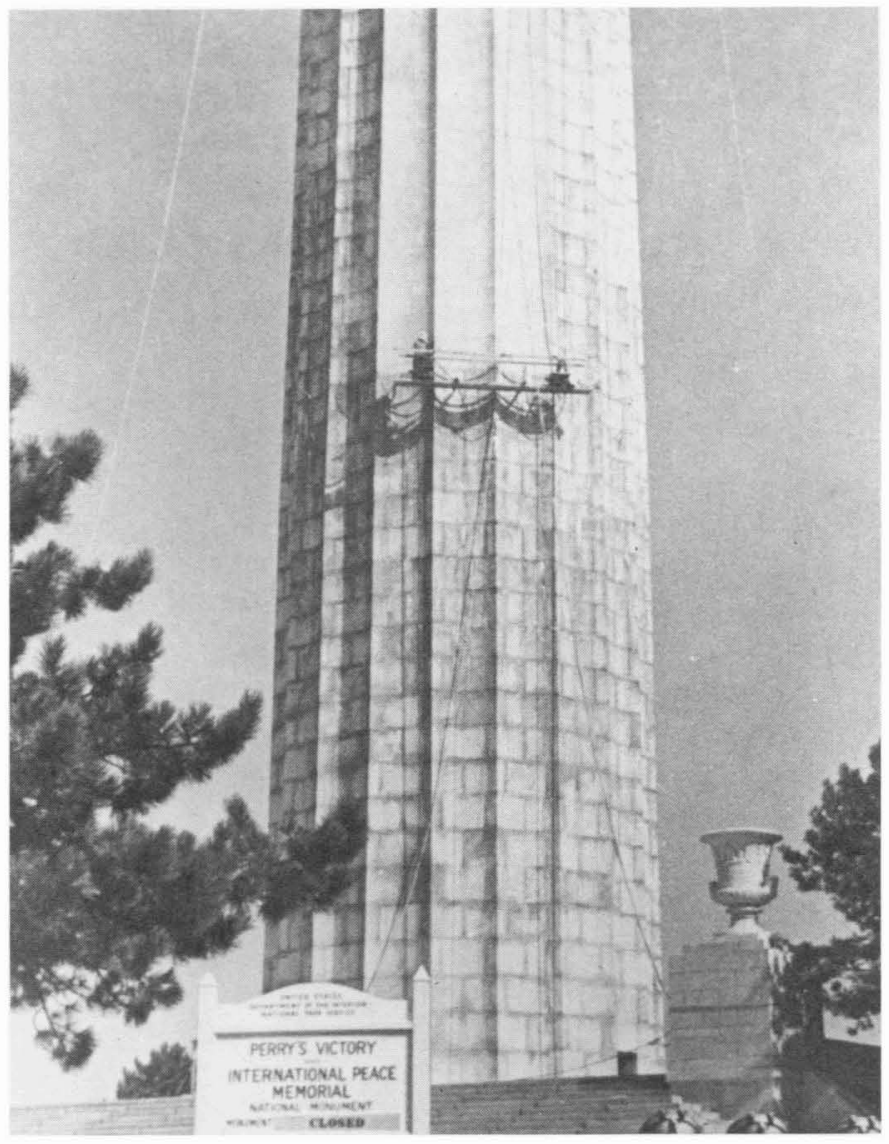

8. Sandblast cleaning (1953).

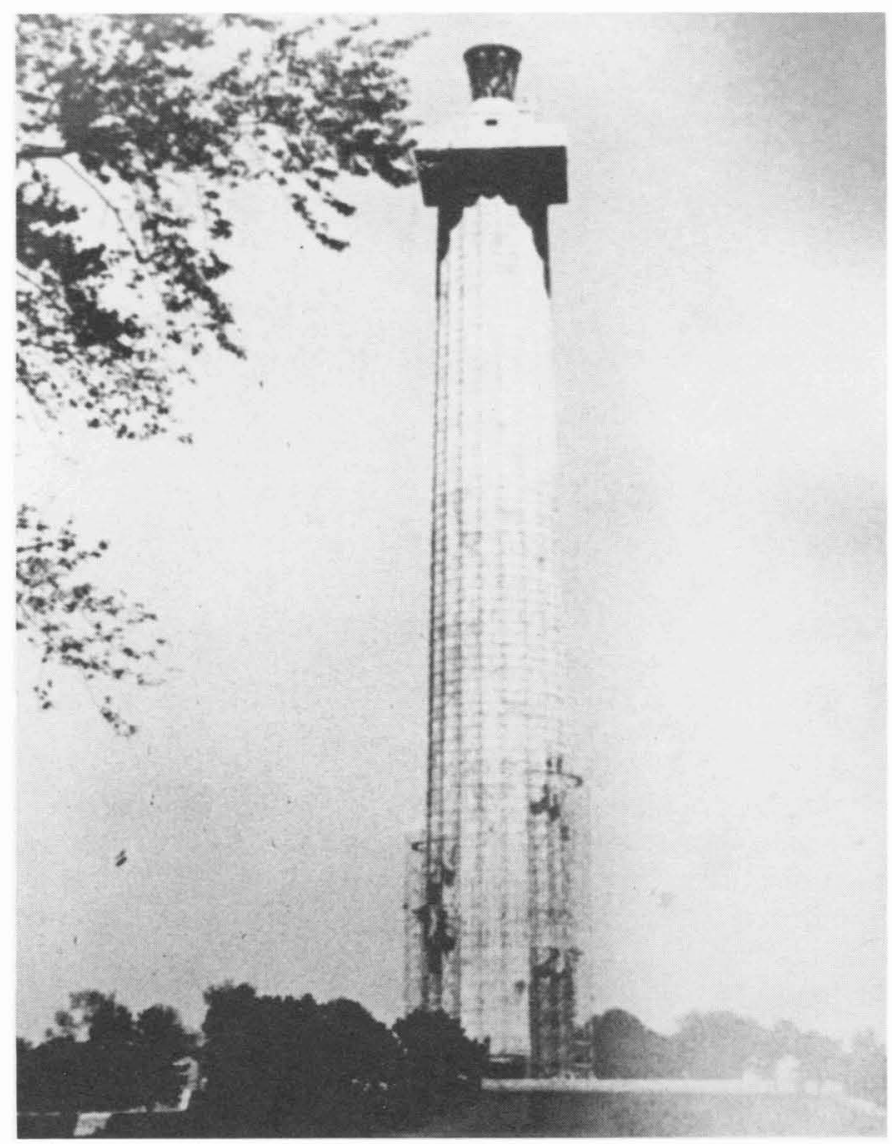

10. Exterior cleaning, recaulking, and repointing (1964). 


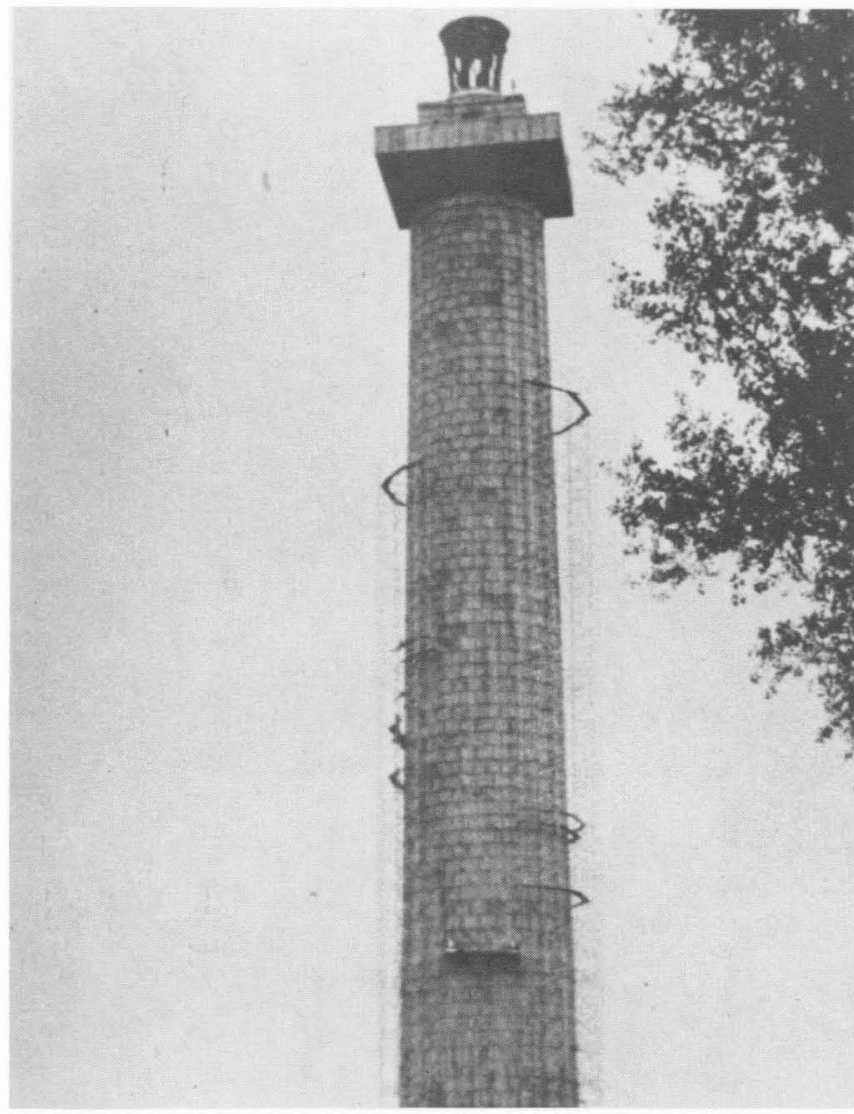

11. Exterior cleaning, recaulking and repointing (1964).

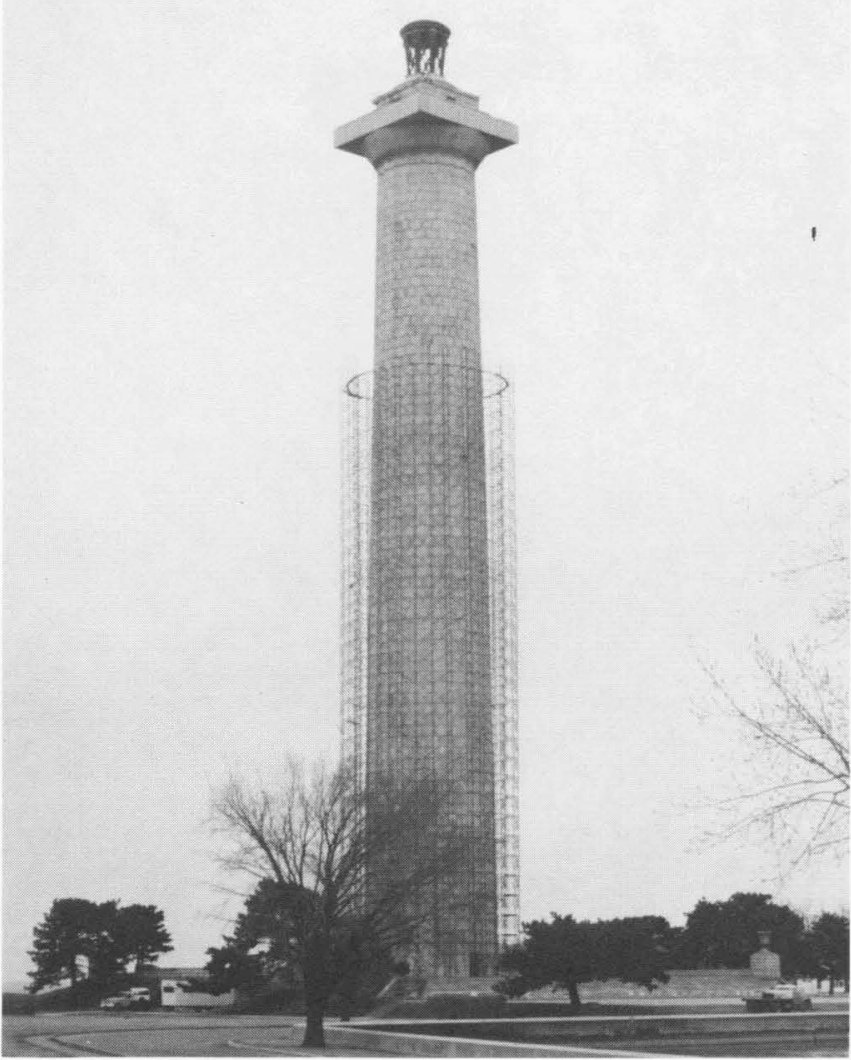

13. Perry Memorial Column (1981).

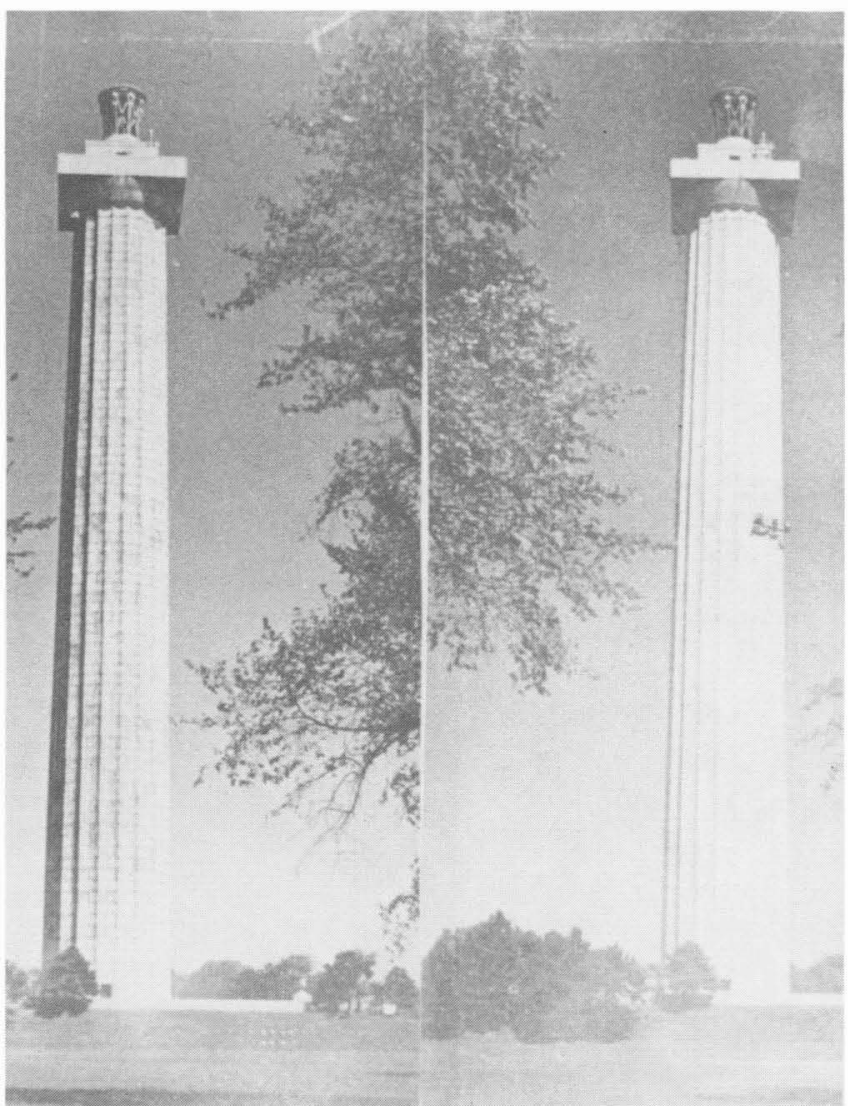

12. Column, prior to and following 1964 work.

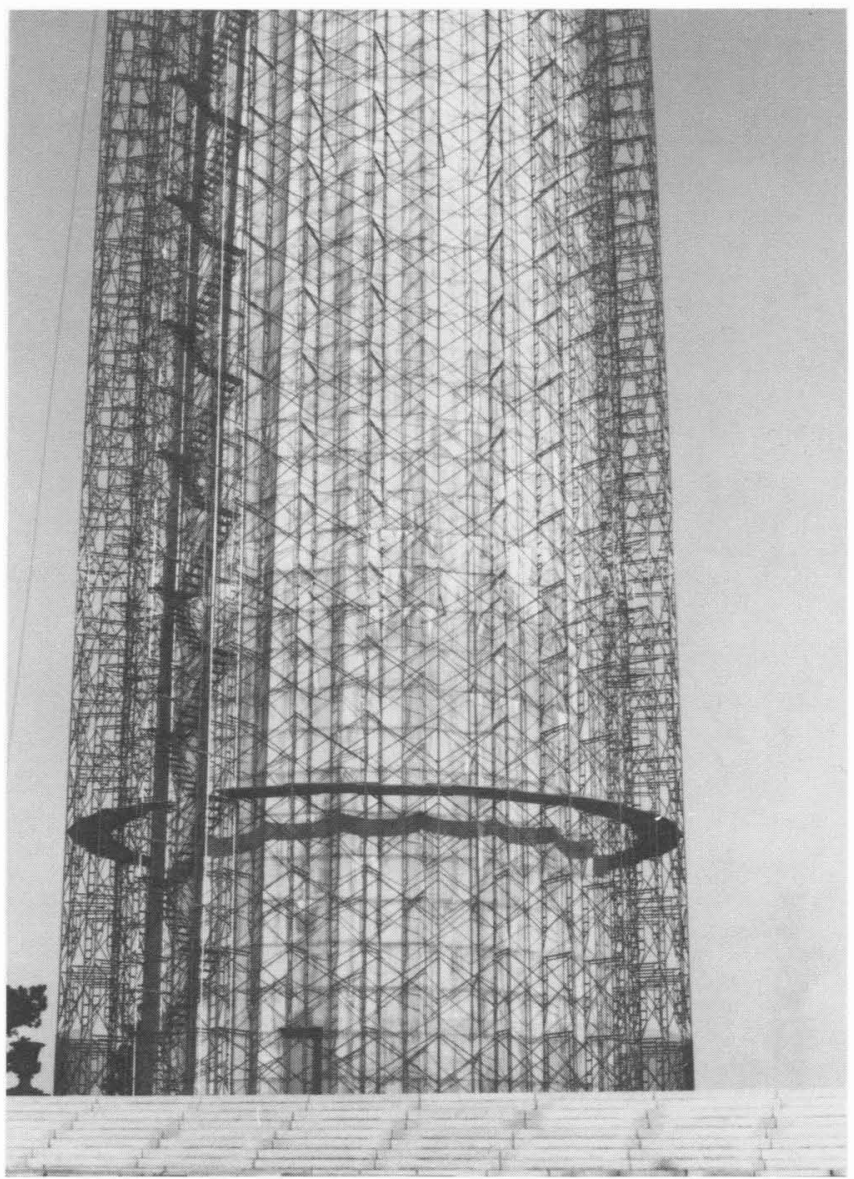

14. Base of Perry Memorial Column (1981). 


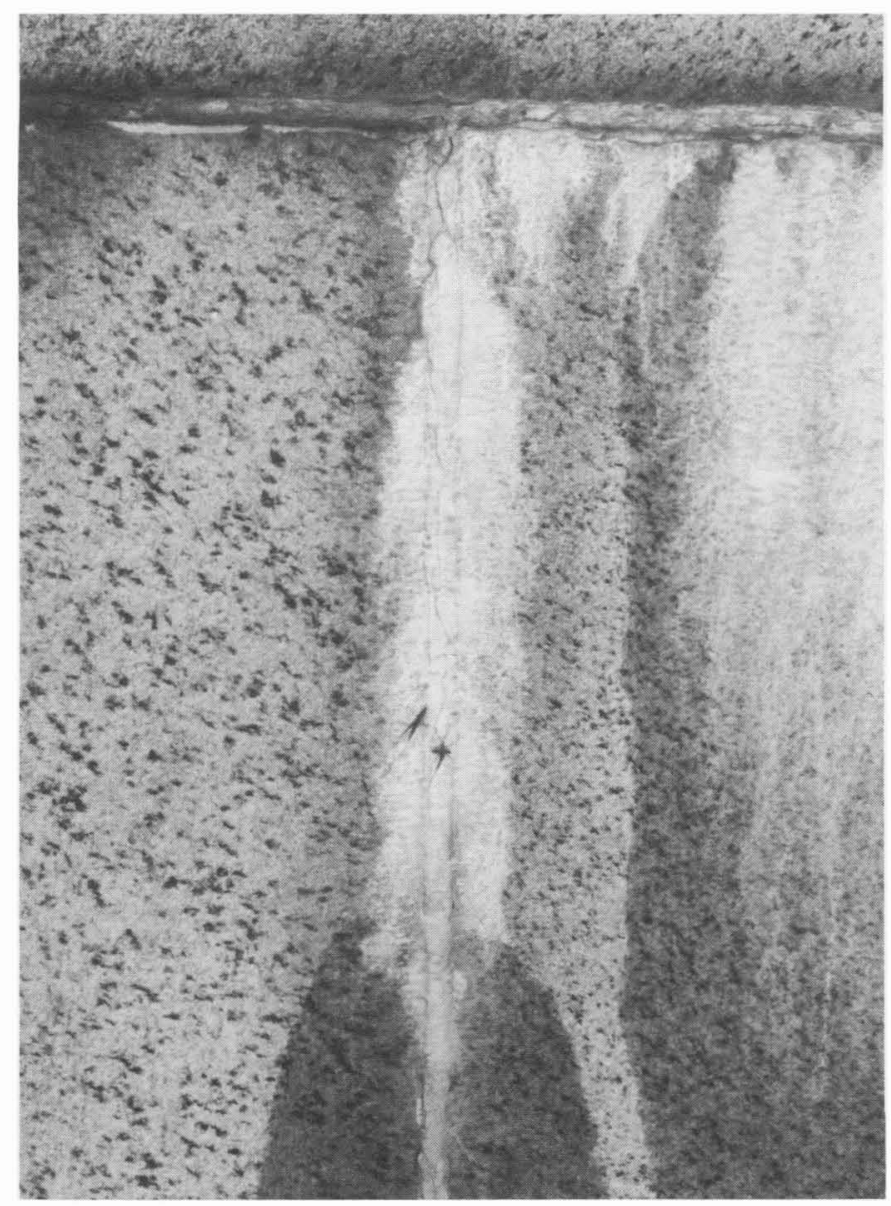

15. Characteristic carbonate/silicate deposit around defective joint.

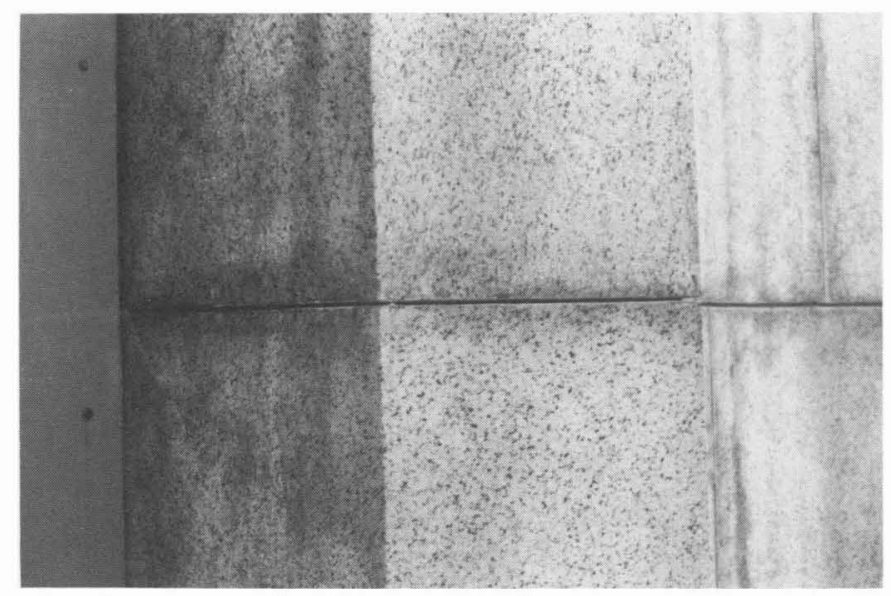

16. Characteristic discoloration around open joint.

these calcium silicate compounds carried in solution and absorbed into the granite which appear to be the cause of the discoloration generally found around the joint edges and sometimes on the ashlar faces (Fig. 15). This discoloration, like the carbonate deposits, also includes air-borne particulates, but it is not predominantly a surface stain. This can be verified by the unsuccessful cleaning tests previously executed using low abrasive blasting on these areas.

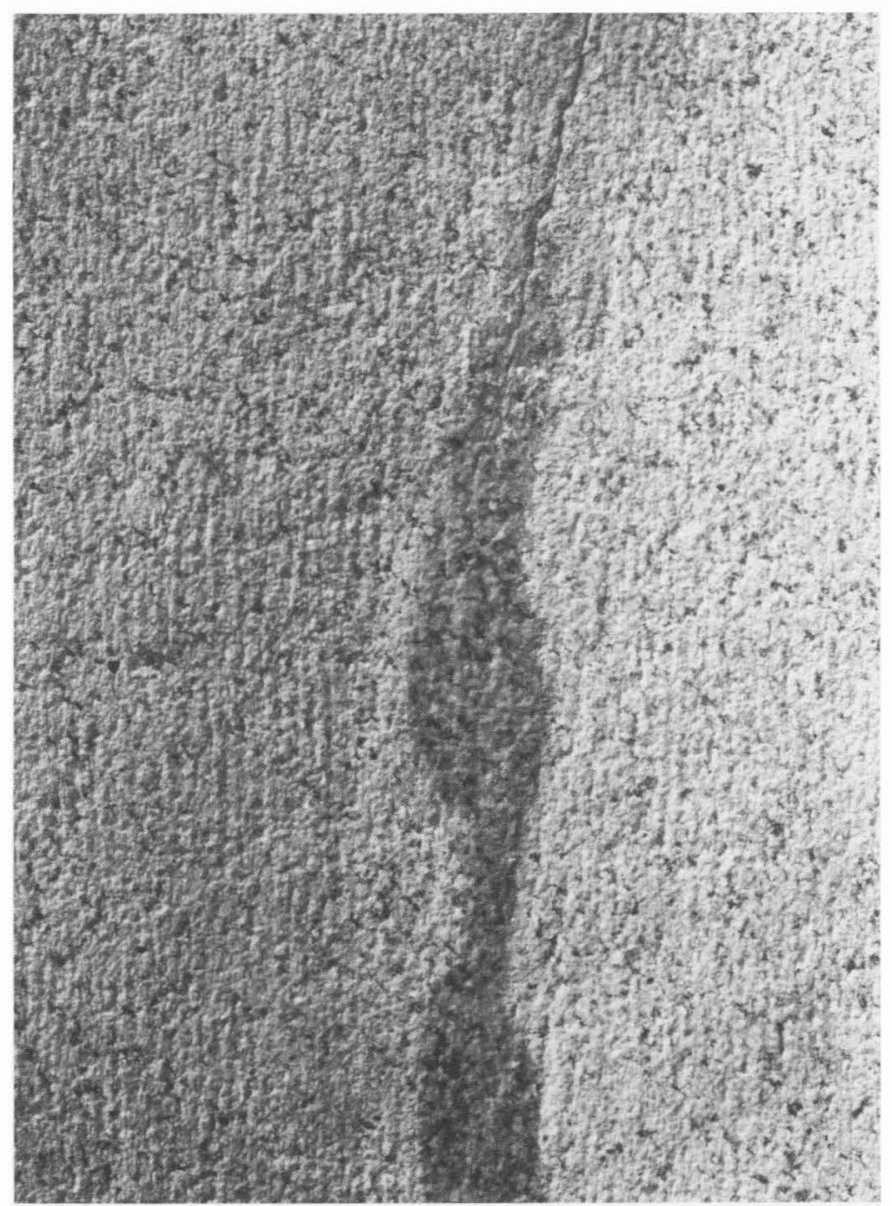

17. Crack oozing water.

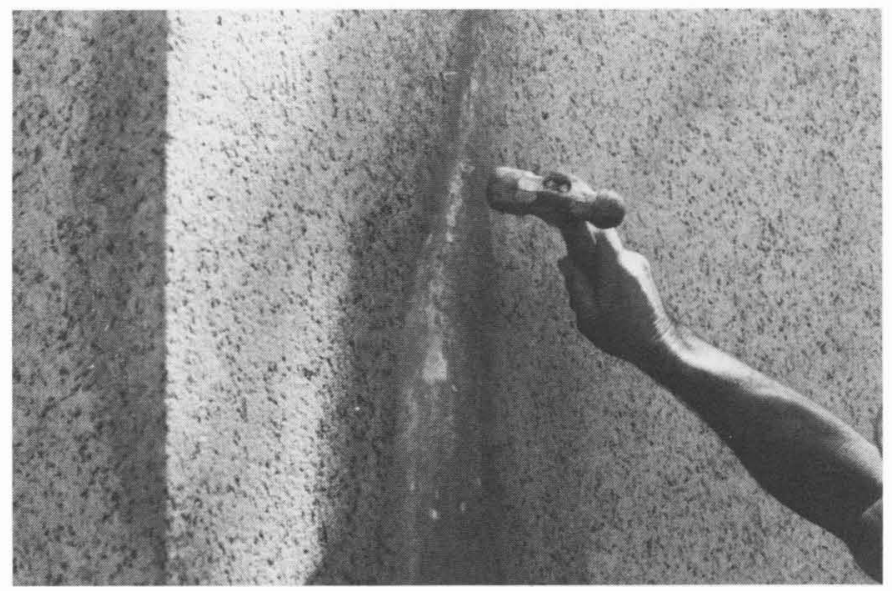

18. Ineffective hand removal of deposits.

\section{Structural Deterioration}

Structural problems were evidenced visually in the column by numerous cracks on the exterior and several large wide cracks on the interior. This cracking was addressed in previous structural reports and attributed to internal stresses caused by daily temperature changes in the wall of the shaft.

This assessment is probably accurate, especially as it 
relates to the effects of thermal expansion. The coefficient of linear expansion of granite is less than that of concrete by a factor of approximately 1.5 and 2.0 respectively. Theoretically, with the same degree of heat, the concrete should expand more than the granite and thus cause a greater cracking in the exterior surface of the granite. However, this does not appear to be the case, for the largest cracks appear on the interior brick veneer through the concrete. The reason for this is that solar radiation falls primarily on the granite exterior and the thermal coefficient for heat transmission is low, somewhat more than half that of Portland cement, allowing the granite to heat up and expand long before there is heat enough to appreciably expand the concrete. Thus, a lateral stress is placed on the concrete through the granite keys, causing vertical cracks on the interior surface.

\section{Conservation Testing Program}

The appropriate removal of the disfiguring surface deposits and general cleaning of the column's exterior masonry was an essential cumponent of the overall plan for the restoration and rehabilitation of the monument at the Perry's Victory site. Based on the information collected, it was concluded that the formation of carbo-

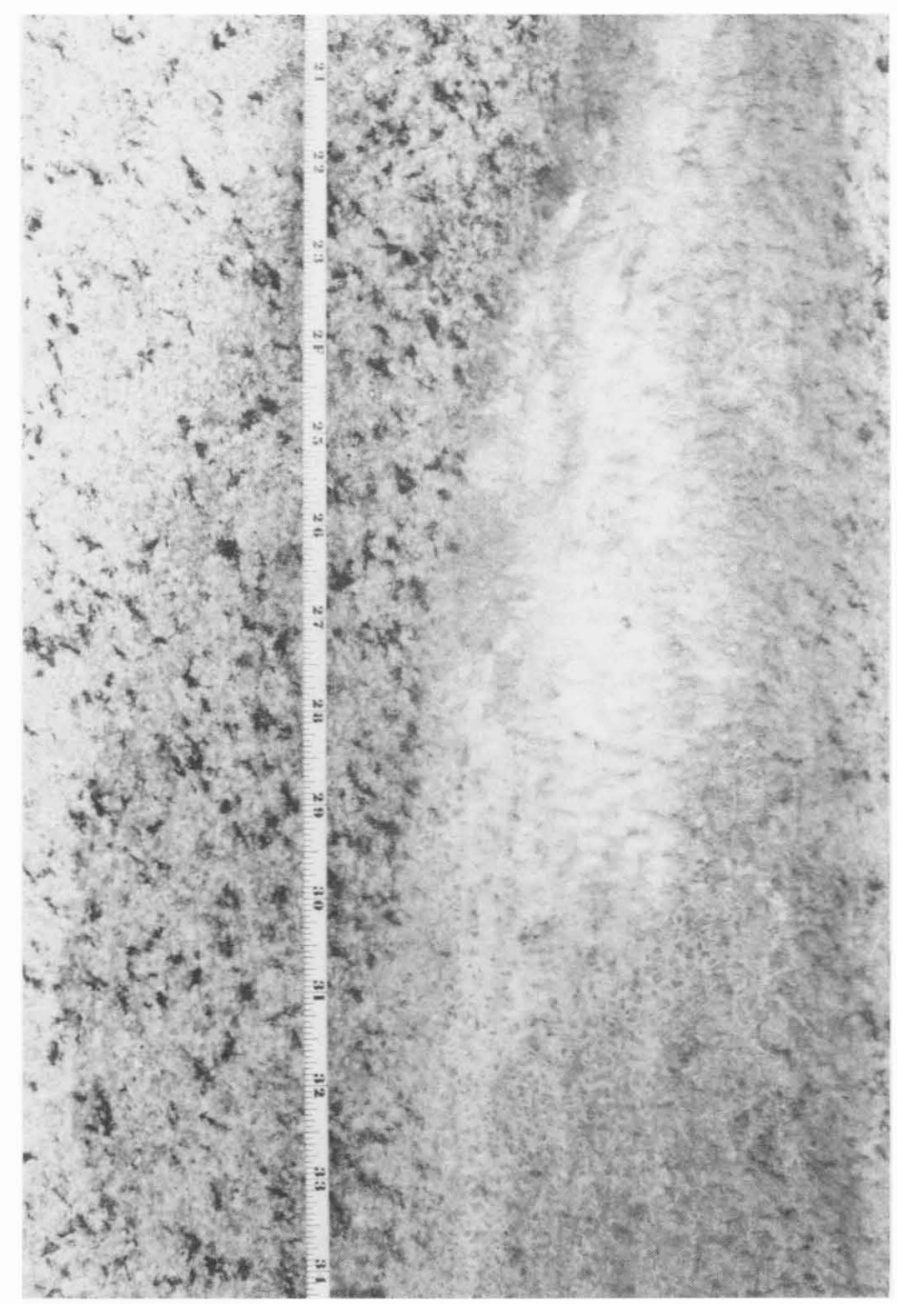

19. Area prior to 50-psi cleaning with flint shot sand (A1) and slag (B1). nate and silicate deposits on the exterior surface would continue to be a problem as long as the leaching of water through the column was allowed to continue.

Although this conservation study was concerned with both the cause and effect of this staining phenomenon, field and laboratory testing was confined to the selection of the most suitable method of removing the surface deposits. Successful cleaning will only be insured, however, if the monument is kept internally dry and/or internal water is allowed to drain through it without contact with the granite facing. The more subtle sub-surface discoloration attributed to complex silicate deposits will require further examination and testing to develop suitable removal techniques when, and if, the column can be kept dry.

Of the cleaning techniques practiced by the building industry, only two methods were selected for review and comparison as possible treatments for stain removal: chemical cleaning with acidic aqueous solutions and low-pressure abrasive cleaning.

Chemical cleaning with acidic solutions prepared with hydrofloric acid could, in theory, be used effectively to remove the heavy acid-soluble deposits formed on the granite. These materials, however, can produce a

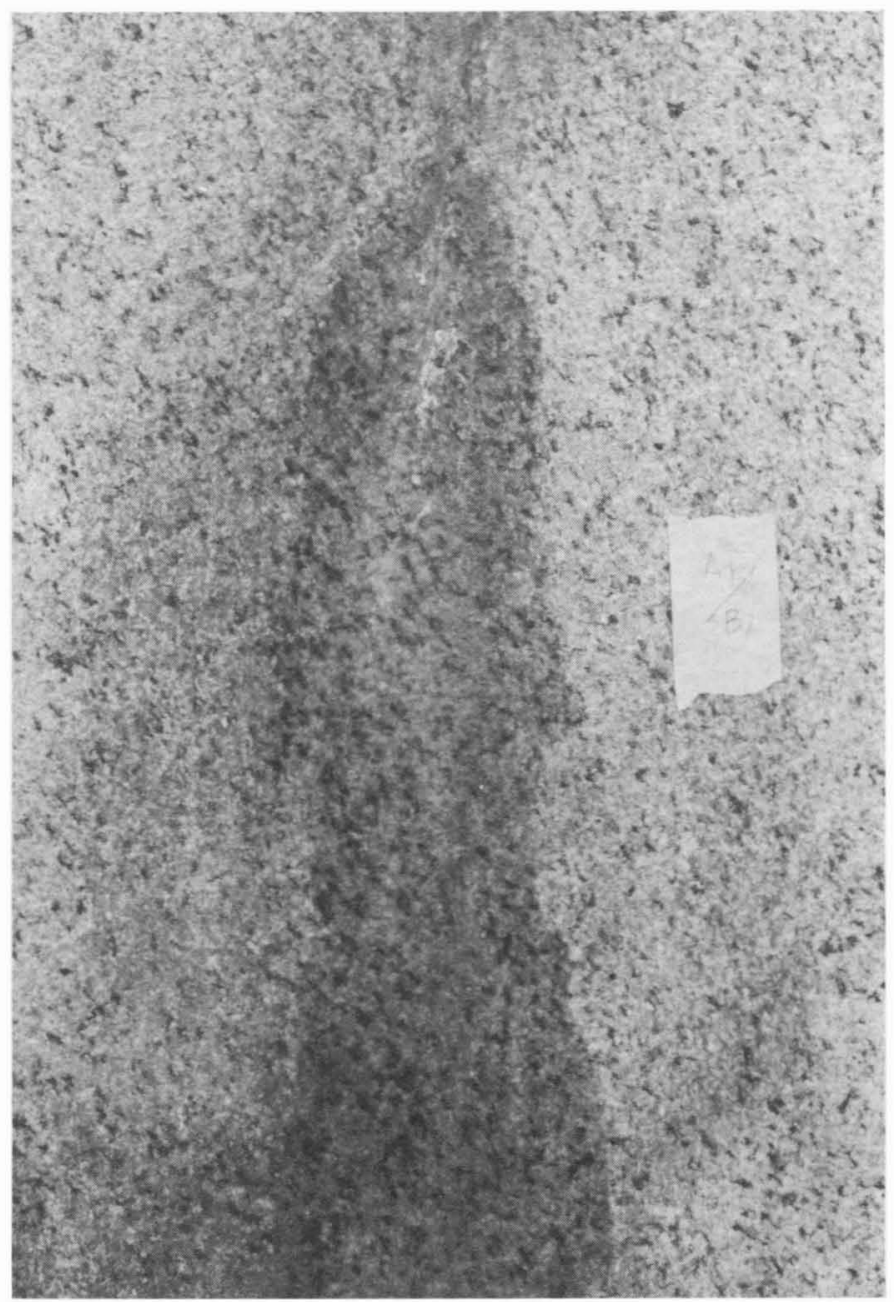

20. Area after 50-psi cleaning with flint shot sand (A1) and slag (B1). 
yellow discoloration or 'burning' which occurs as a result of the oxidation of available iron oxide in the granite. Although water repellant sealers could be applied to prevent further oxidation after such treatments, the high moisture content within the column could cause discoloration to occur around any defective joint or opening. In addition, these coatings would have a limited life (5-8 years), thereby requiring continual reapplication. Moreover, the high concentration of acid cleaners required to remove effectively these accretions would attack the silicate minerals in the granite, causing etching, and visual distortion of the surface. The use of an acidic cleaning system in combination with a water repellant would be potentially dangerous to the granite itself, extremely difficult in application, and expensive in maintenance upkeep, assuming reapplication of the repellant at regular intervals. Furthermore, the system would require large amounts of water for application and rinsing/neutralization which would necessitate the complete weatherproofing of the column prior to treatment. In summary, the use of such a system seems overly complicated and inappropriate to the situation.

Abrasive cleaning was selected as the most suitable method for further study and inclusion in the testing program. This was largely determined by the favorable results achieved by previous abrasive tests conducted as well as the success of related field testing at other sites. Although often misused, the technique can be a safe and effective treatment for specific cleaning situations. Abrasive cleaning is accomplished by impacting the masonry with an air-abrasive or air-water-abrasive jet. This action results in mechanical scrubbing of the surface. Controlling factors are: size, shape, and hardness of the abrasive aggregate; pressure of the air or air-water jet; nozzle design; and distance and angle of the nozzle from the surface. Proper selection of these conditions determines the success or failure of the cleaning process, and can be established only through field testing.

The introduction of water in the cleaning process primarily aids in rinsing down any loose material on the wall, and in controlling the dust associated with extremely fine abrasive aggregates and with pulverized

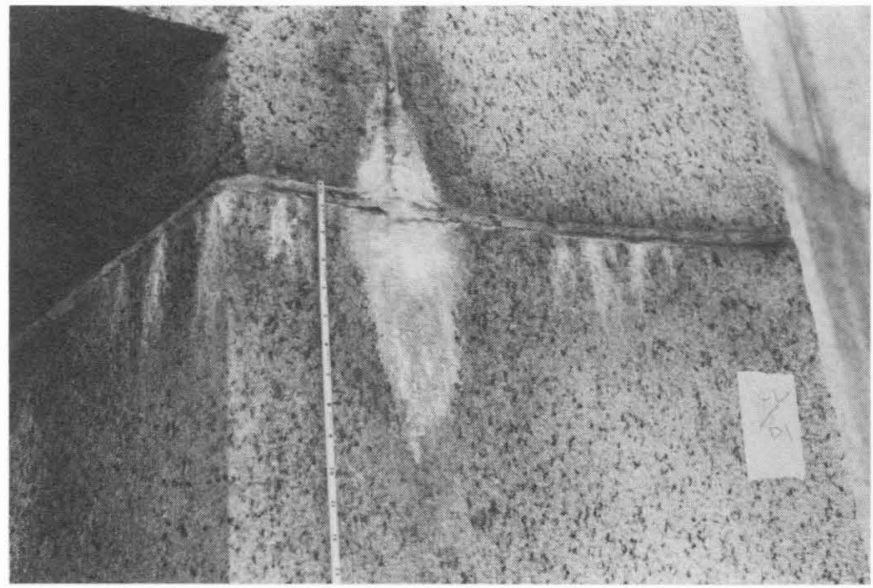

21. Area prior to 50-psi cleaning with walnut shells (C1) and sharpedged sand (D1). surface material. (This is particularly important in confining the amount of siliceous dust produced by sandblasting.) Contrary to general belief, water does not significantly "cushion" the impact of the abrasive particles. The most significant negative feature of wet abrasive cleaning is the problem of water penetration into open joints and fissures. Previous tests executed on the column masonry indicate that wet aggregate cleaning at approximately 100 psi was effective in removing most of the accretive deposits of calcium carbonate and silicate, while a water wash rinse at 100 psi removed the surface particulates. Neither cleaning methods were successful in removing the discoloration at the joint edges.

Further testing was conducted in June, 1981, in order to assess the results achieved using four (4) different aggregates: fine milled silica sand (Fig. 31), fine sharp-edged silica sand (Fig. 34), glass slag (fine) (Fig. 32), and milled walnut shells (coarse) (Fig. 33) applied at 50, 100 and $150 \mathrm{psi}$. These aggregates were selected due to their distinct differences in composition, particle shape and particle size, as well as their general availability to the building industry. Results of the testing program were evaluated on the basis of:

- the efficacy of the techniques in the removal of the deposits,

- the effect of the techniques on the granite,

- the degree of safety for the operator and public, and

- the relative cost.

Testing was conducted at selected locations on the second, ninth, and tenth courses of the stonework where surface deposits were heaviest. All equipment was of standard industrial design and all tests were run dry using a No. 4 nozzle with approximately a $40^{\circ}$ dispersal. Nozzle distance from the stone surface was kept constantly at approximately 12 inches and held at $90^{\circ}$ to the masonry surface.

\section{Observations (Figs. 19-30)}

At all pressures of 50,100 and $150 \mathrm{psi}$, all four aggregates were successful in removing even the heaviest

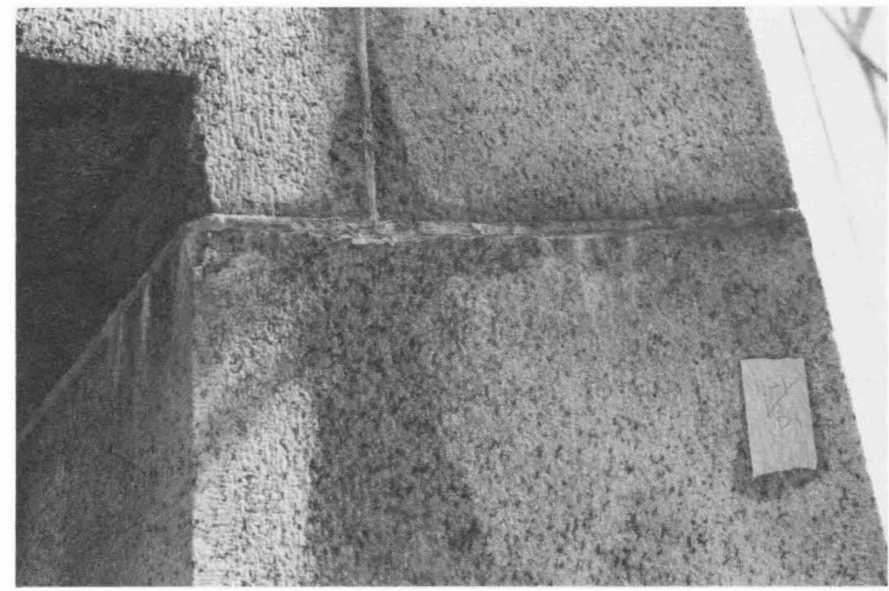

22. Area after 50-psi cleaning with walnut shells (C1) and sharpedged sand (D1). 


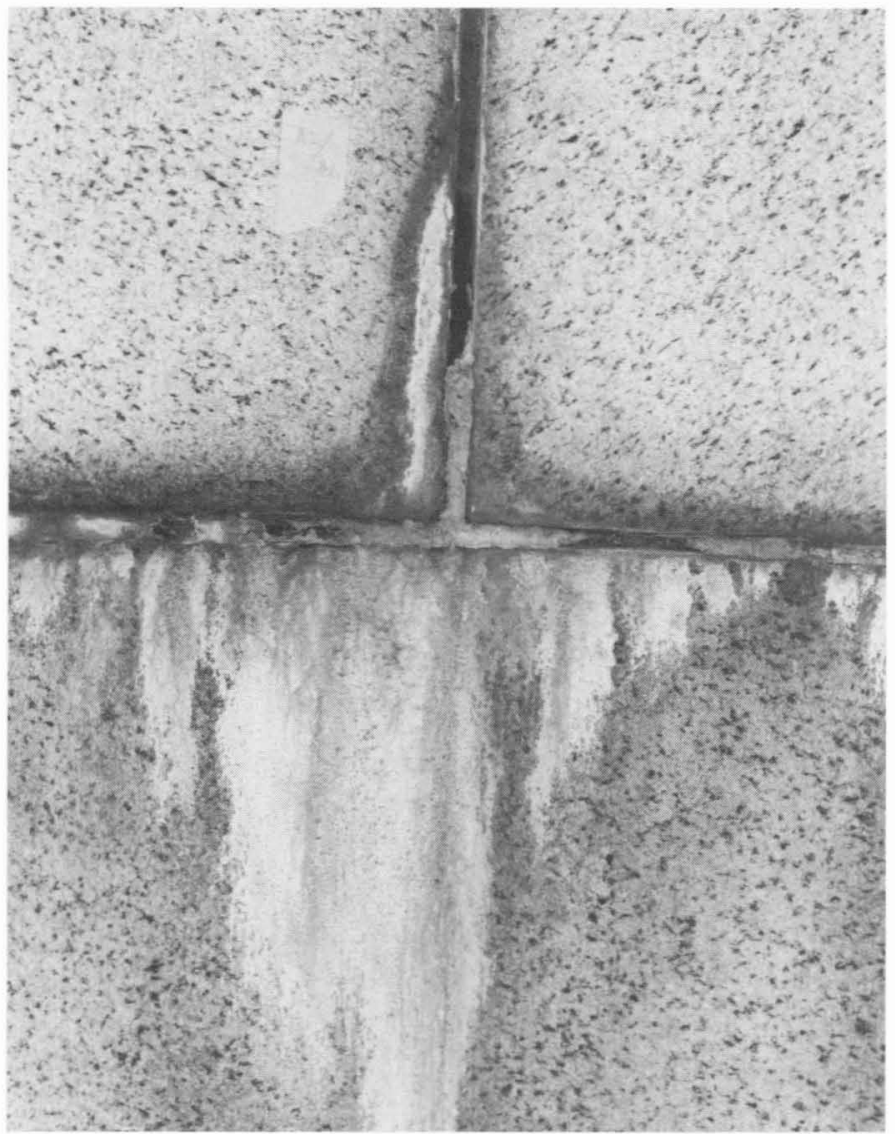

23. Area prior to 100 -psi cleaning with flint shot sand (A2) and slag (B2).

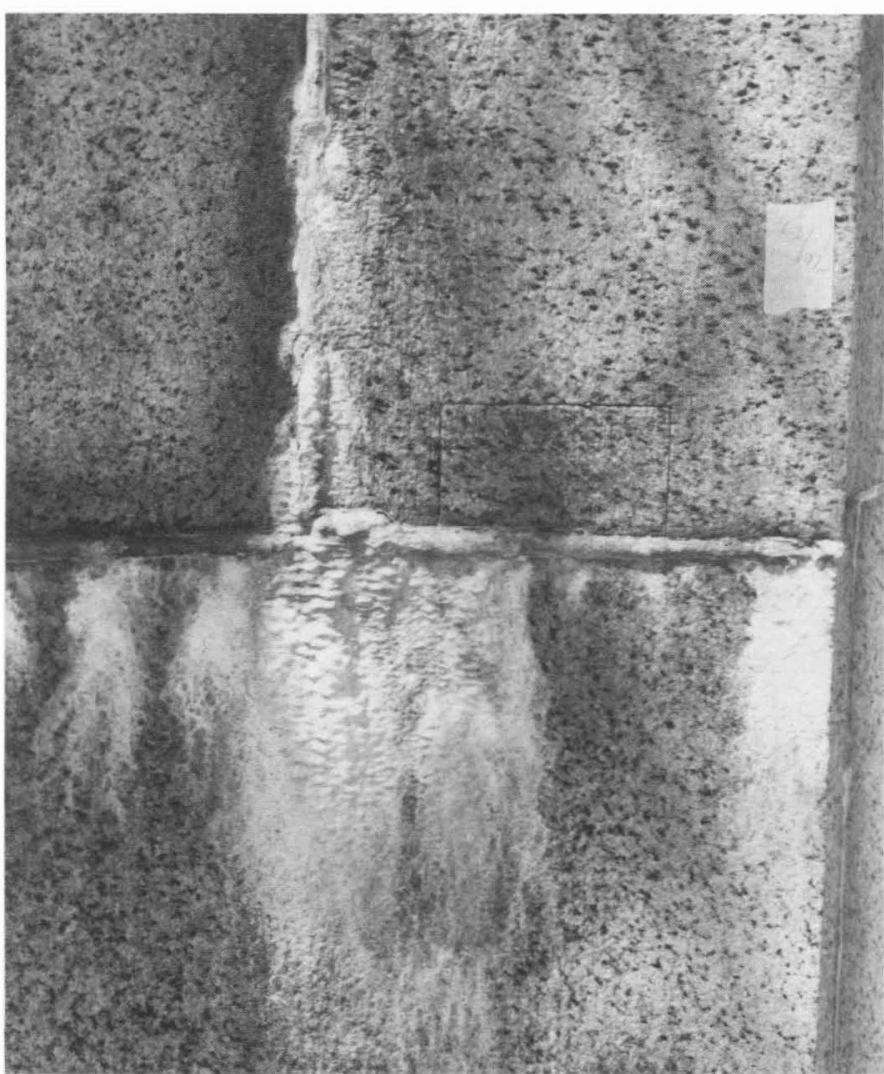

25. Area prior to $\mathbf{1 0 0}$-psi cleaning with walnut shells (C2) and sharpedged sand (D2).

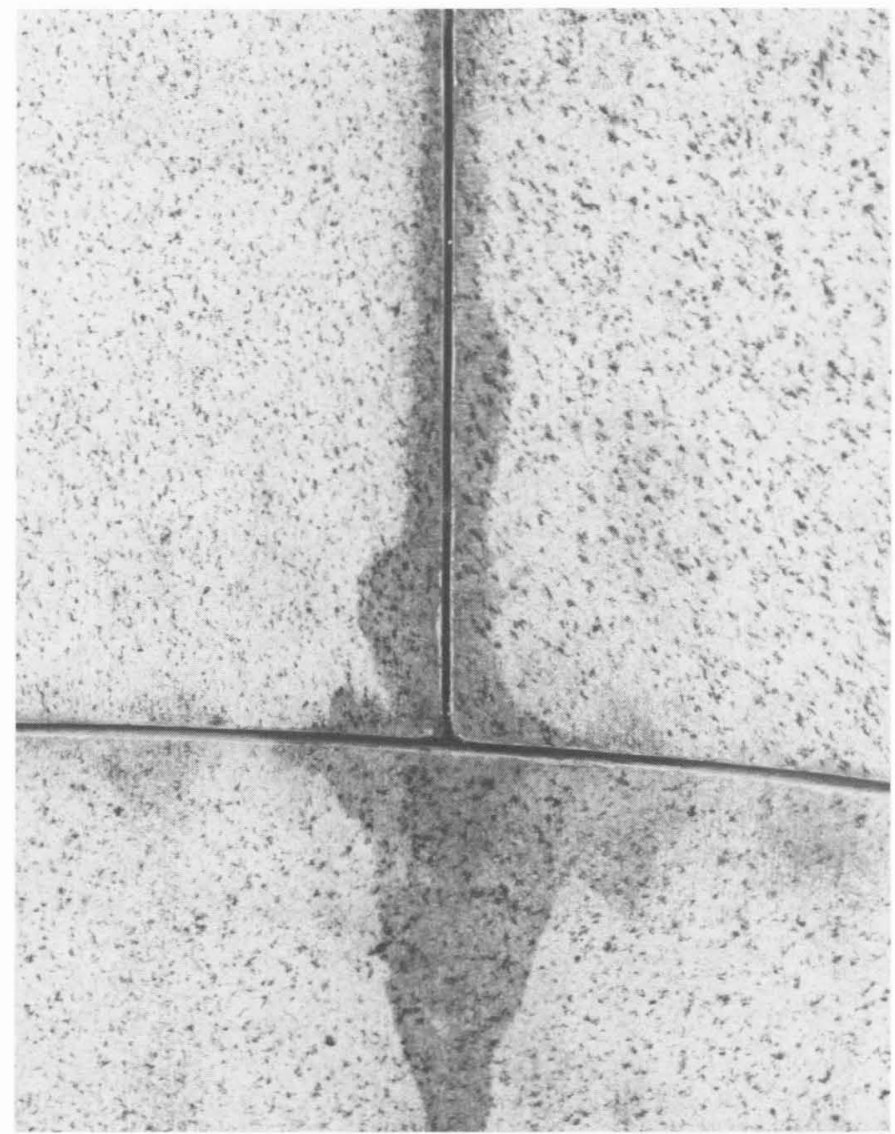

24. Area after 100-psi cleaning with flint shot sand (A2) and slag (B2).

surface deposits. Of the aggregates, only the walnut shells exhibited reduced efficiency (increase in time and volume of material) at lower pressures. Slight surface abrasion resulted with all four aggregates at 150 psi only when the application distance was decreased to less than 4 inches from the surface of the stone. Due to the consistent results obtained in the removal of the surface deposits with all aggregates at 100 psi and at a distance

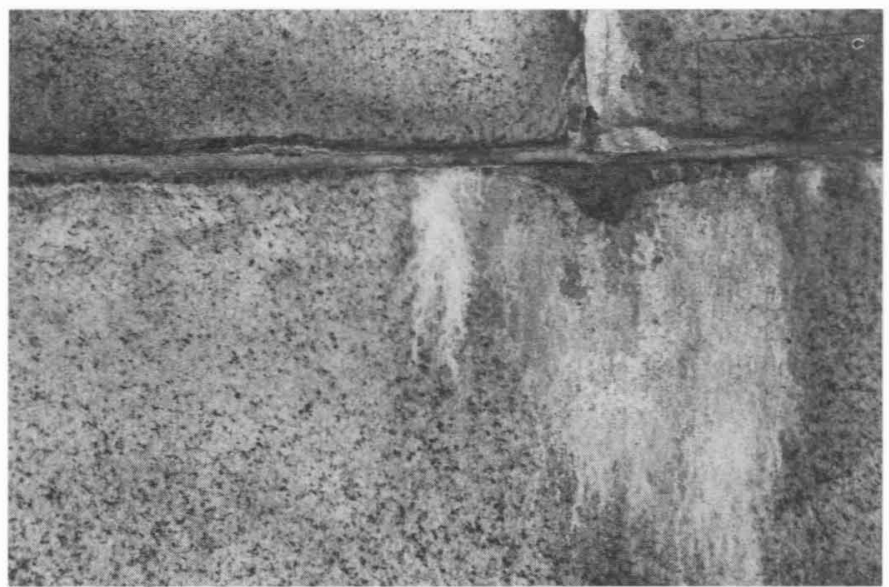

26. Area after 100-psi cleaning with walnut shells (C2) and sharpedged sand (D2). 


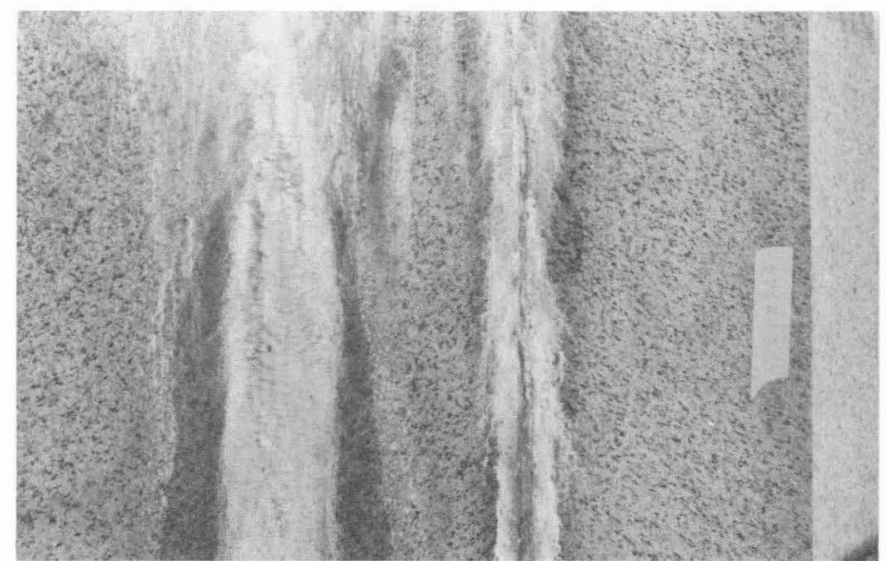

27. Area prior to 150-psi cleaning with flint shot sand (A3), slag (B3), walnut shells (C3), and sharp-edged sand (D3).

between $4^{\prime \prime}$ and $12^{\prime \prime}$, initial selection of the most appropriate technique was by cost and safety factors.

A comparison of cost for the four aggregates revealed that the price of the two sands and the glass slag was approximately equal $(8-11 థ / \mathrm{lb})$ while the walnut shells ranged from 2 to $2-1 / 2$ times in price $(22 \Phi / / b)$. Although the walnut shells could be recycled, the time and cost in constructing such a system would need to be considered. With these parameters being equal, the only significant difference between the sand and slag systems was the potential health hazard associated with silica sandblasting. While this problem could be ameliorated by using a wet-aggregate (hydro-silica) system, it would require the sealing of the column joints and fissures prior to cleaning. It was therefore recommended that all surface deposit cleaning be conducted dry. General surface cleaning with a low pressure water wash could eventually be conducted only after the sealing of the open joints and fissures was accomplished.

In order to determine the effects of the individual tests on the granite substrate, a combination of field and lab techniques was employed. All surfaces were exam-

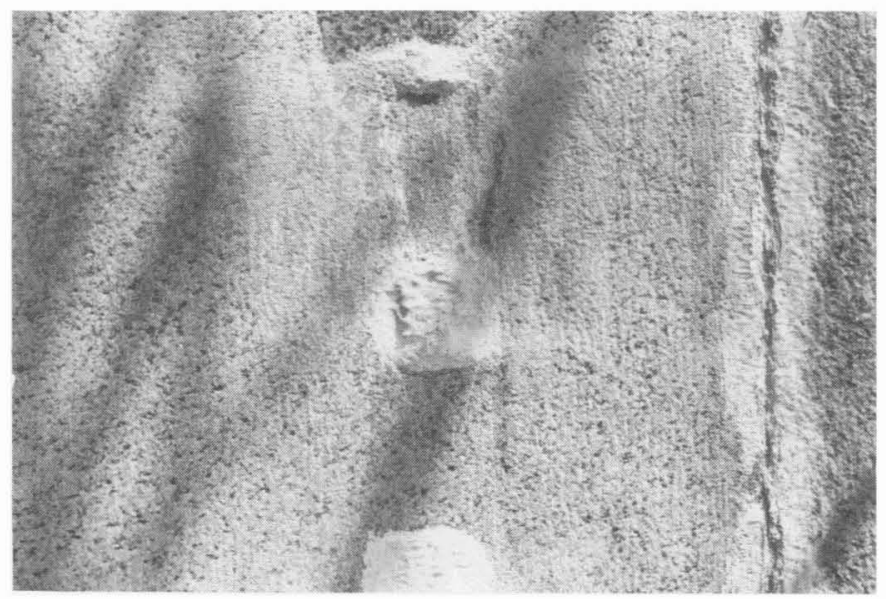

29. Area after 150-psi cleaning with walnut shells (C3) and sharpedged sand (D3).

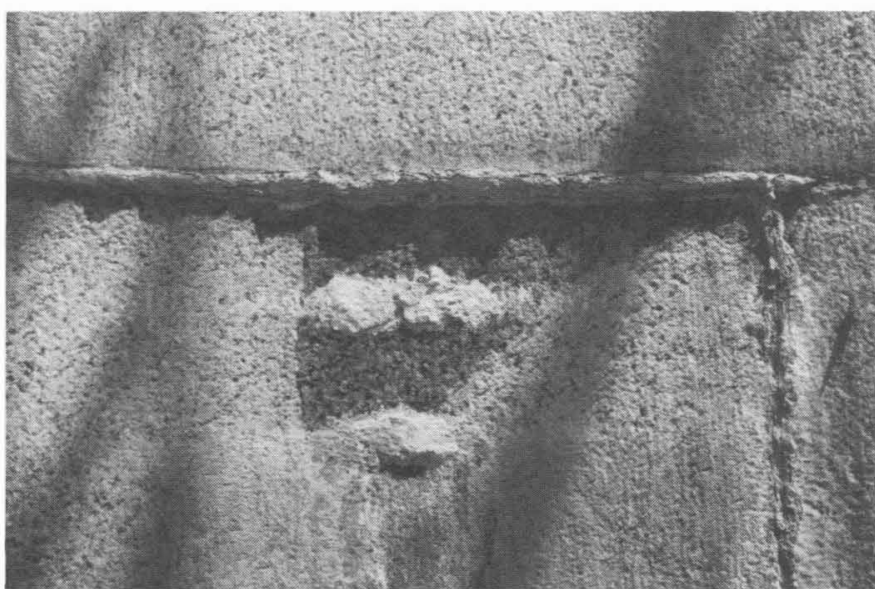

28. Area after 150-psi cleaning with flint shot sand (A3) and slag (B3).

ined after testing, in situ, under low power (30x) magnification in order to observe any surface deformation and/or carbonate/silicate residue. Once a specific treatment was selected for further study (based on this and general observation), a precise measurement of the amount of surface loss due to the abrasion of the granite surface was calculated.

Based on the aforementioned criteria, tests per-

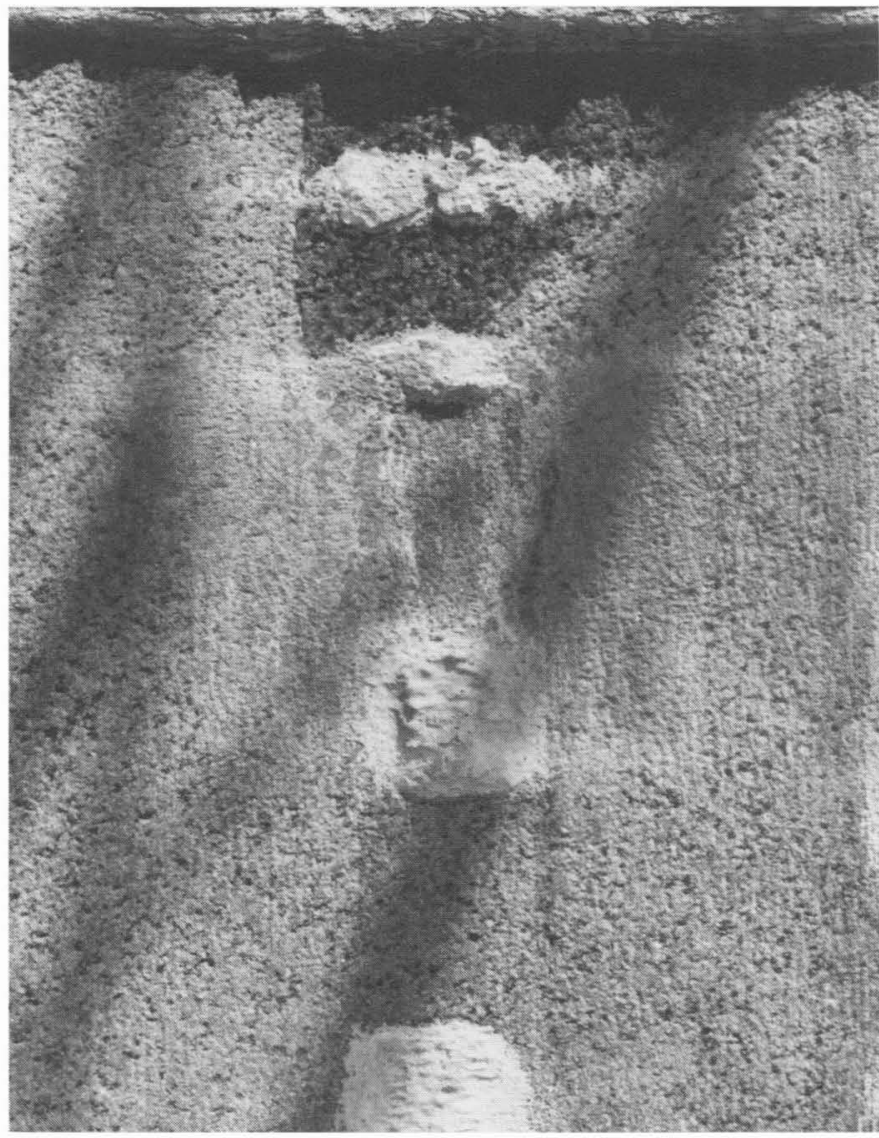

30. Comparative results of 150 -psi cleaning with all four aggregates. 


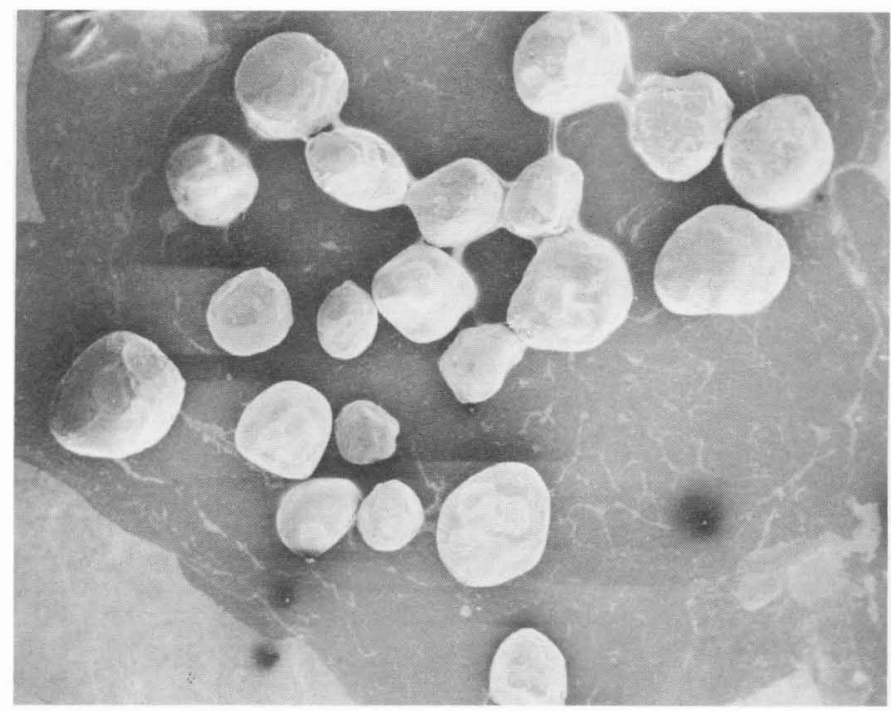

31. Flint shot silica sand (mag.: 20x).

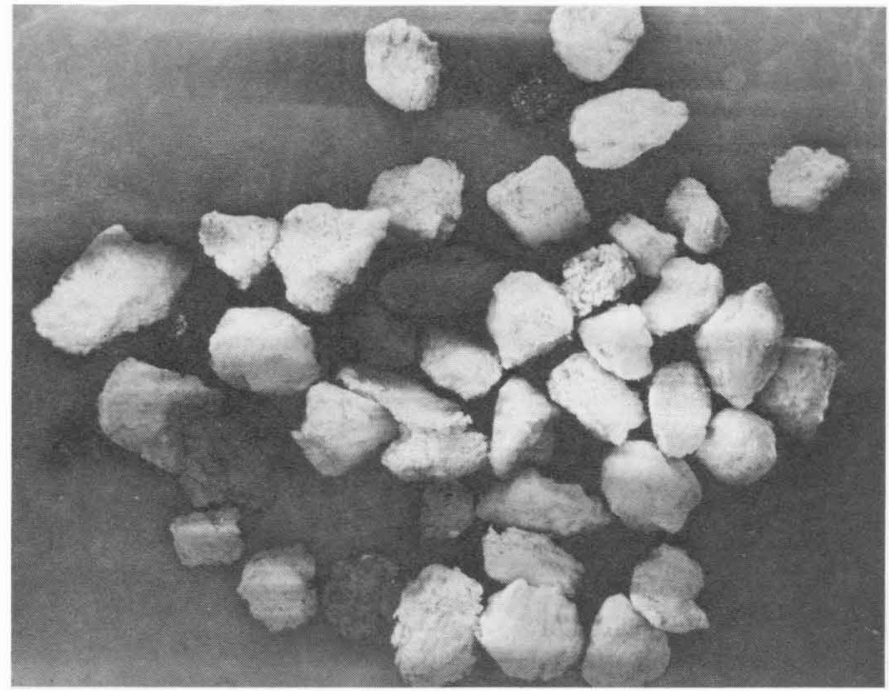

33. Milled walnut shells (mag.: 20x).

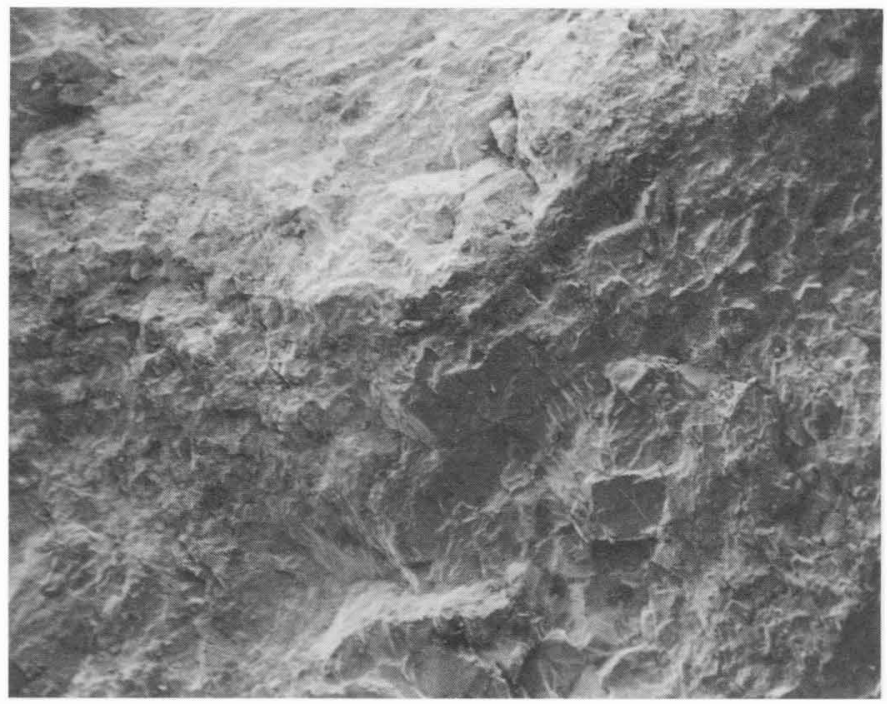

35. Scanning electron photomicrograph of granite control surface (mag.: 50x).

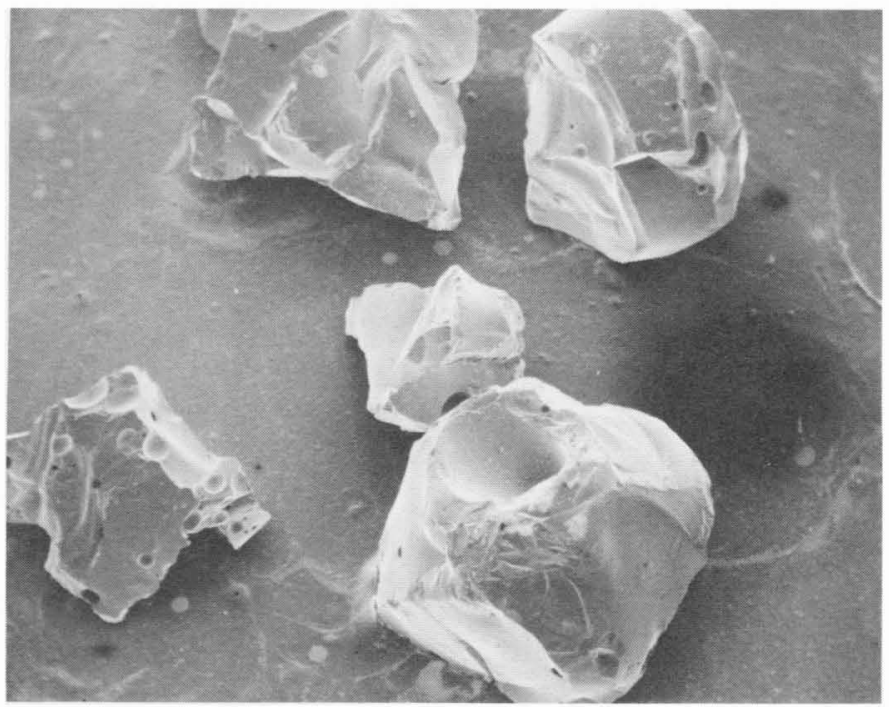

32. Black Beauty slag (mag.: 20x).

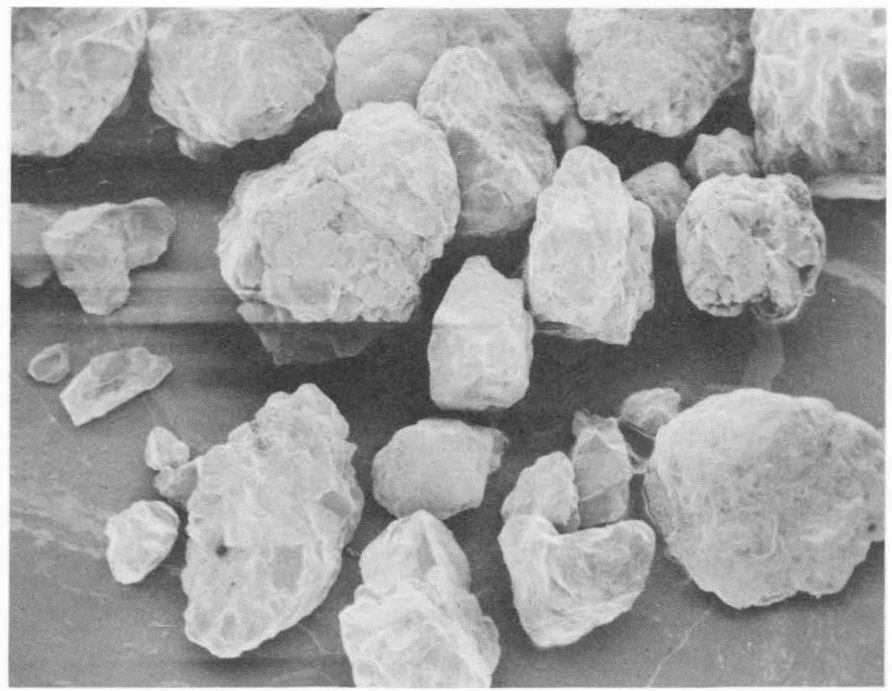

34. Fine, sharp-edged silica sand [Series F] (mag.: 20x).

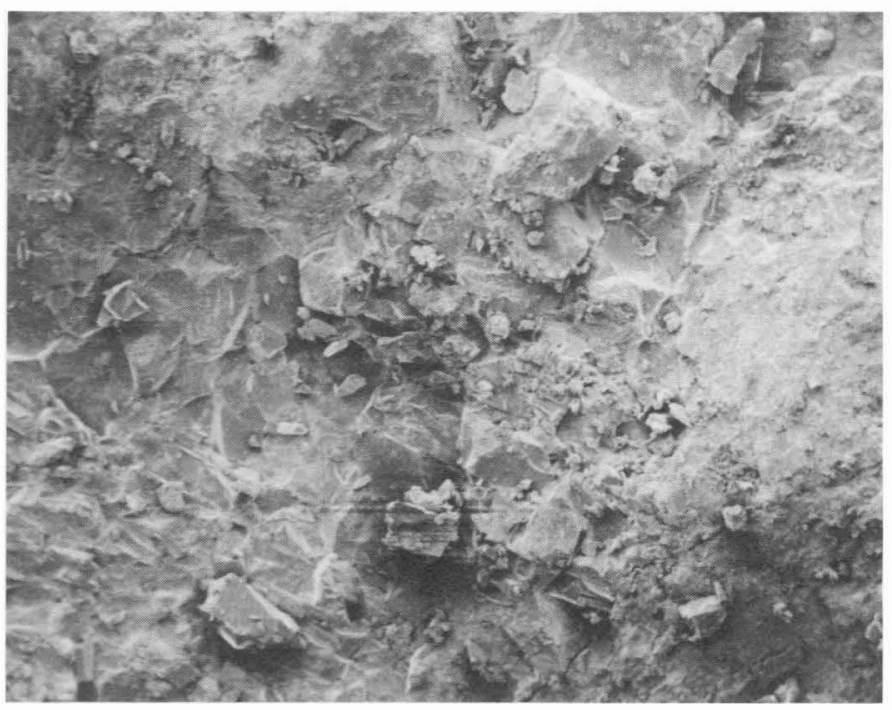

36. Scanning electron photomicrograph of granite control surface after 150-psi cleaning with slag (mag.: 50x). 
formed with Black Beauty slag (course No. 8-10) at 100 psi were initially selected as the most appropriate cleaning system for the removal of the carbonate-silicate deposits. Final testing of this system was performed by subjecting a sample of Milford granite (taken from the observation gallery parapet) of known weight and surface area (test face only) to the same test parameters (Black Beauty at 100 psi at $12^{\prime \prime}$ ). Only time was held at an arbitrarily determined constant of 15 seconds. After exposure, the sample was cleaned free of debris and reweighed and the change in volume for the given surface area was calculated to give the average change in depth or loss of surface material.

Results from the above experiment indicate that a change in average surface depth of $0.16 \mathrm{~mm}$ or $0.027 \%$ surface loss was recorded from an area approximately $16.32 \mathrm{~cm} .{ }^{3}$ This difference was not observable in the field at $30 x$ magnification and could only be seen under the Scanning Electron Microscope (Figs. 35 \& 36).

\section{Conclusions and Recommendations}

Based on the results of the method tested, it was concluded that dry abrasive cleaning with slag aggregate at 100 psi was the most suitable technique for the effective removal of the calcium carbonate/silicate deposits, without causing physical or chemical damage to the granite substrate.

According to the guidelines established, the method selected was found to be a highly efficient localized treatment, completely removing typical deposits of approximately $2^{\prime}$ long in 60 seconds with no observable surface abrasion $(0.16 \mathrm{~mm})$ or sub-surface fracturing of the granite. The effect of the method on mortar pointing or elastomeric sealants was not considered as it was recommended that the cleaning be executed only after the joints had been opened and the column allowed to dry out.

All abrasive methods are relatively hazardous to the operator and involve the use of protective clothing and respirator equipment. Using a large particle aggregate avoids the problem of wind drift which could create a public safety hazard and cause damage to personal property. Fortunately, the monument was freestanding and isolated by open grounds, creating a controllable barrier between the work and the public.

Prior to cleaning, it was strongly recommended that all joints be raked, thus allowing the column to dry out as much as possible. This was critical since during cleaning tests, it was observed that freshly cleaned areas around joints and open cracks immediately began to leak, thus beginning the entire process of redeposition all over again (Fig. 17). Once the column was allowed to dry out, an alkali-resistant primer sealant and closed cell backer rod was installed to prevent the discharge of any further water. Abrasive cleaning was then executed and the finish sealant installed and tooled. This system also accommodated the decision to wash the entire monument with a low pressure water rinse to remove any carbonate dust residue and overall surface particulates after deposit removal.

The proper diagnosis and hence appropriate treatment of any outdoor monument requires a systematic approach involving a knowledge of the original materials and technologies employed, a history of the condition, deterioration and maintenance of the structure over time, and the preparation of a full condition survey noting type and extent of deterioration. Taken together, this information system allows for the accurate diagnosis of material failure, and in conjunction with carefully planned and executed testing and evaluation, ensures the selection of the most appropriate treatment for the conservation and interpretation of the monument. It has been towards establishing such an approach that the above study was executed.

\section{Acknowledgements}

The author would like to thank E. Blaine Cliver for his technical assistance and support and Randy Biallas for his continual interest in the project. 